\title{
Efficacy, tolerability, and safety of an oral enzyme combination vs diclofenac in osteoarthritis of the knee: results of an individual patient-level pooled reanalysis of data from six randomized controlled trials
}

\author{
This article was published in the following Dove Press journal: \\ Journal of Pain Research \\ 4 November 2016 \\ Number of times this article has been viewed
}

\author{
Michael A Ueberall' \\ Gerhard HH \\ Mueller-Schwefe ${ }^{2}$ \\ Rainer Wigand ${ }^{3}$ \\ Ute Essner ${ }^{4}$
}

'Institute of Neurological Sciences, Nuremberg, ${ }^{2}$ Interdisciplinary Center for Pain and Palliative Care Medicine, Göppingen, ${ }^{3}$ Interdisciplinary Center for Rheumatology and Immunology, Frankfurt, ${ }^{4} \mathrm{O}$.Meany Consultancy, Hamburg, Germany
Correspondence: Michael A Ueberall Institute of Neurological Sciences, 5I Nordostpark, 904II Nuremberg, Germany

Tel +49 9I। 21773760

Fax +49 9II 21773761

Email michael.ueberall@ifnap.de
Objective: To compare efficacy, safety, and tolerability of an oral enzyme combination (OEC) containing proteolytic enzymes and bioflavonoid vs diclofenac (DIC), a nonselective nonsteroidal anti-inflammatory drug in the treatment of osteoarthritis of the knee.

Materials and methods: This was an individual patient-level pooled reanalysis of patientreported data from prospective, randomized, double-blind, parallel-group studies in adult patients with moderate-to-severe osteoarthritis of the knee treated for at least 3 weeks with OEC or DIC. Appropriate trials were identified with a systemic literature and database search. Data were extracted from the original case-report forms and reanalyzed by a blinded evaluation committee. The primary end point was the improvement of the Lequesne algofunctional index (LAFI) score at study end vs baseline. Secondary end points addressed LAFI response rates, treatment-related pain-intensity changes, adverse events, and laboratory parameters.

Results: Six trials were identified that enrolled in total 774 patients, of whom 759 had postbaseline data for safety analysis, 697 ( $n=348 / 349$ with OEC/DIC) for intent to treat, 524 for per protocol efficacy analysis, and 500 for laboratory evaluation. LAFI scores - the primary efficacy end point - decreased comparably with both treatments and improved with both treatments significantly vs baseline (OEC $12.6 \pm 2.4$ to $9.1 \pm 3.9$, DIC $12.7 \pm 2.4$ to $9.1 \pm 4.2$, effect size $0.9 / 0.88 ; P<0.001$ for each). In parallel, movement-related 11 -point numeric rating-scale pain intensity improved significantly $(P<0.001)$ and comparably with both treatments from baseline $(6.4 \pm 1.9 / 6.6 \pm 1.8)$ to study end (3.8 $\pm 2.7 / 3.9 \pm 2.5)$. Overall, 55/81 OEC/DIC patients of the safetyanalysis population $(14.7 \% / 21.1 \%, P=0.022)$ reported $90 / 133$ treatment-emergent adverse events, followed by premature treatment discontinuations in $22 / 39$ patients $(5.9 \% / 10.2 \%, P=0.030)$. Changes in laboratory parameters were significantly less with OEC vs DIC: on average $18.8 \%$ vs $86.3 \%$ of patients presented a decrease with respect to hemoglobin, hematocrit, or erythrocyte count $(P<0.001)$, and $28.2 \%$ vs $72.6 \%$ showed an increase in AST, ALT, or GGT $(P<0.001)$.

Conclusion: When compared with DIC, OEC showed comparable efficacy and a superior tolerability/safety profile associated with a significantly lower risk of treatment-emergent adverse events, related study discontinuations, and changes in laboratory parameters.

Keywords: oral enzyme combination, diclofenac, osteoarthritis, randomized controlled trial, meta-analysis 


\section{Background}

Osteoarthritis (OA) of the knee is the most prevalent cause of pain and locomotor disability worldwide, and affects on average $25 \%$ of the general population in the Western world, with increasing prevalence with age. ${ }^{1,2}$ About $80 \%$ of OA patients suffer from arthritis-attributable limitations of activity, $25 \%$ cannot perform major activities of daily living, $14 \%$ of adults with knee OA require help with routine needs, and $11 \%$ require help with personal care. ${ }^{3}$

Recommendations for the management of knee OA have been issued by different national, continental, and global scientific authorities, and differentiate pharmacologically between background (basic) and advanced treatment strategies. ${ }^{411}$ While basic pharmacological approaches address predominantly chondroprotective and antinociceptive mechanisms, advanced interventions for OA patients in whom these background treatments have failed and who suffer from moderate-to-severe pain focus on anti-inflammatory interventions to relieve pain and to improve daily functioning and quality of life.

Oral nonsteroidal anti-inflammatory drugs (NSAIDs) scientifically known to be highly efficacious for OA pain - are traditionally listed as first-line agents in combination with the recommendation to select the most appropriate nonselective or COX2-selective NSAIDs with respect to their safety profiles and patients' individual risk factors, concomitant diseases, and medical conditions to improve their safety and tolerability. While generally safe when used at low doses and in the short term, ${ }^{12-14}$ NSAIDs - COX2-selective or not - are frequently associated with significant side effects and increase the risk of serious adverse events (AEs) involving the gastrointestinal (GI), cardiovascular, and renal systems, especially when used long term at higher doses in patients with concomitant diseases or in the elderly, which is often the case in patients with OA. ${ }^{15-17}$

In the past few decades, complementary medicines with COX-independent pain-relieving and anti-inflammatory effects - such as an oral enzyme combination (OEC) consisting of the natural compounds trypsin, bromelain, and rutoside trihydrate - has become increasingly popular among OA patients in Europe and North America. In contrast to its popularity and patient-reported beneficial effects under daily practice conditions, scientific evidence for its efficacy remains rather limited.

Several randomized controlled trials have uniformly reported an improved safety/tolerability profile of OEC vs diclofenac (DIC), as well as comparable analgesic and antiphlogistic efficacy in patients with knee OA. ${ }^{18-20}$ However, sample sizes were small, and data-reporting and data-evaluation procedures varied from trial to trial, leaving several question marks with respect to the general transferability of these study data into daily practice.

Due to this situation, the managing boards of the German Pain Association (Deutsche Gesellschaft für Schmerzmedizin [DGS]) and the German Pain League (Deutsche Schmerzliga [DSL]) commissioned the Institute for Neurosciences, Algesiology, and Pediatrics to develop a concept for and to execute a pooled individual patient-level meta-analysis of data from prospective randomized controlled trials comparing OEC vs DIC in patients with OA of the knee.

\section{Materials and methods}

\section{Study identification}

Appropriate studies were identified from the Cochrane Library, Cochrane Database of Systematic Reviews, Medline (1966 onward), Embase (1980 onward), Science Citation Index, International Pharmaceutical Abstracts, and via a hand search of journals and conference proceedings for randomized controlled trials with OEC. Relevant bibliographies were checked, and the marketing authorization and registration holder of the OEC product (Mucos Pharma GmbH, Berlin, Germany) was contacted and asked to provide unrestricted access to the original individual patient data (IPD).

Trials were included only if: 1) they were conducted in accordance with the principles of the Declaration of Helsinki and Good Clinical Practice; 2) they conformed to relevant national and local ethical and regulatory requirements valid at the time of the study; 3 ) they were prospectively conducted; 4) they were based on a randomized, double-blind design; 5) they were actively controlled vs DIC; 6) patients provided written informed consent for the collection, analysis, and release of anonymized data prior to study enrollment; and 7) unrestricted access to the original raw data was available and granted to allow the implementation of a pooled IPD reanalysis. Overall, six trials were identified that fulfilled the selection criteria mentioned and for which raw IPD were made available (see Table 1). ${ }^{19-24}$

\section{Study characteristics Design}

All studies followed a prospective, randomized, actively controlled, double-blind, parallel-group design and were conducted in multiple centers and different countries in accordance with Good Clinical Practice guidelines. Investigational 
Table I Study overview and patient disposition

\begin{tabular}{|c|c|c|c|c|c|c|c|c|c|c|}
\hline \multirow[t]{2}{*}{$\overline{\text { Study }}$} & \multirow{2}{*}{$\begin{array}{l}\text { Tmt } \\
\text { (weeks) }\end{array}$} & \multirow{2}{*}{$\begin{array}{l}\text { RND } \\
\text { (n) } \\
\end{array}$} & \multirow{2}{*}{$\begin{array}{l}\begin{array}{l}\text { Safety } \\
\text { population }\end{array} \\
\text { n (\% RND) } \\
\end{array}$} & \multirow{2}{*}{$\begin{array}{l}\text { ITT } \\
\text { population } \\
\text { n (\% RND) } \\
\end{array}$} & \multirow{2}{*}{$\begin{array}{l}\text { PP } \\
\text { population } \\
\text { n (\% RND) } \\
\end{array}$} & \multirow{2}{*}{$\begin{array}{l}\text { Lab } \\
\text { population } \\
\text { n (\% RND) }\end{array}$} & \multicolumn{2}{|c|}{ Tmt } & \multicolumn{2}{|c|}{ Daily dose } \\
\hline & & & & & & & OEC & DIC & OEC (ETC) & DIC (mg) \\
\hline Herrera $^{22}$ & 3 & 59 & $59(100)$ & $59(100)$ & $52(88.1)$ & 0 & + & + & $3 \times 2$ & $150 / 100$ \\
\hline Klein and Kullich" & 3 & 73 & $73(100)$ & $73(100)$ & $66(90.4)$ & $46(63)$ & + & + & $3 \times 2$ & $150 / 100$ \\
\hline Singer et a $\left.\right|^{19}$ & 3 & 63 & $63(100)$ & $63(100)$ & $57(90.5)$ & $15(23.8)$ & + & + & $3 \times 2$ & $150 / 100$ \\
\hline Roth and Stauder ${ }^{23}$ & 6 & 268 & $268(100)$ & $241(89.9)$ & $153(57.1)$ & $222(82.8)$ & + & + & $3 \times 2$ & 100 \\
\hline Akhtar et $\mathrm{al}^{20}$ & 6 & 116 & $103(88.8)$ & $98(84.5)$ & $56(48.3)$ & $80(69)$ & + & + & $3 \times 2$ & 100 \\
\hline Bolten et $\mathrm{al}^{24}$ & 12 & 195 & $193(99)$ & $163(83.6)$ & $139(7 \mid .3)$ & $137(70.3)$ & + & + & $3 \times 2$ & 150 \\
\hline$\overline{\text { OEC }}$ & $3-12$ & 381 & $375(98.4)$ & 348 (9I.3) & $265(69.6)$ & $247(64.8)$ & & & & \\
\hline DIC & $3-12$ & 393 & $384(97.7)$ & $349(88.8)$ & $258(65.6)$ & $253(64.4)$ & & & & \\
\hline Significance & - & - & NS & NS & NS & NS & & & & \\
\hline Overall & $3-12$ & 774 & $759(98.1)$ & $697(90.1)$ & $523(67.6)$ & $500(64.6)$ & & & & \\
\hline
\end{tabular}

Abbreviations: Tmt, treatment; RND, randomized; ITT, intent-to-treat; PP, per protocol; Lab, laboratory; OEC, oral enzyme combination; DIC, diclofenac; ETC, entericcoated tablets; NS, not significant.

medication was prepared and given following a doubledummy approach to make drugs suitable for the double-blind study design.

\section{Subjects}

The number of randomized patients varied from 59 to 268 subjects. Altogether, 774 middle-aged and older adults with moderate-to-severe knee OA who satisfied the following inclusion criteria - common to all studies - were enrolled: 1) age $\geq 18$ years, 2) OA of the knee confirmed by conventional radiography and/or tomography, 3 ) an acute flare in the target joint clinically verified by a swelling of the affected knee upon physical examination, 4) a Lequesne algofunctional index (LAFI) score $>10$ (indicating a "very severe" OA-related handicap), and 5) OA-related knee-pain intensity $\geq 3$ on an 11-point numeric rating scale $\left(\mathrm{NRS}_{11}\right)$ ranging from 0 ("no pain") to 10 ("worst pain conceivable"). Exclusion criteria that were common to all trials identified were: 1) presence of an acute or history of a clinically relevant knee trauma, 2) joint infection, 3) joint surgery or intra-articular injection ("viscotherapy"), 4) rheumatoid arthritis or other diseases causing secondary arthritis (eg, psoriatic arthritis, syphilitic neuropathy, metabolic bone disease, osteoporosis), 5) systemic or intra-articular treatment with corticosteroids within the previous two months, and 6) systemic pharmacotherapy with NSAIDs, COX2 inhibitors, or glucosamine/chondroitin within 2 weeks prior to baseline. In addition, subjects with clinically relevant GI, cardiovascular, hepatic, renal, and/or hematological diseases were excluded, as well as 1) patients with known sensitivity to NSAIDs, oral enzymes, or any ingredients of study medications, 2) pregnant or lactating women, 3) female patients of childbearing age not taking adequate contraception, and 4) patients who had participated in another clinical trial within the previous 30 days. Written informed consent was obtained from each patient prior to study enrolment following an oral and written explanation about the aim and the potential risks of the study.

\section{Treatments}

Study medication consisted of Wobenzym enterically coated tablets containing $48 \mathrm{mg}$ trypsin (from porcine or bovine pancreas; Chemical Abstracts Service [CAS] number 900207-7), $90 \mathrm{mg}$ bromelain (from pineapples [Ananas comosus]; CAS number 37189-34-7), and $100 \mathrm{mg}$ rutoside trihydrate (rutin; from the Japanese pagoda tree [Sophora japonica]; CAS number 250249-75-3) per tablet, DIC enterically coated tablets containing $50 \mathrm{mg}$ DIC sodium per tablet, and matching placebos. OEC dosage was constant among all six studies, and consisted of six tablets per day (two tablets, three times daily), resulting in an overall OEC-delivered proteolytic enzyme activity of 7,290 International Pharmaceutical Federation units per day according to the International Commission on Pharmaceutical Enzymes. ${ }^{25}$ DIC dosage varied between studies: three had a reference-dose regimen of $150 \mathrm{mg}$ DIC (one tablet, three times daily) in the first week, followed by $100 \mathrm{mg}$ DIC (one tablet, twice daily) in the remaining treatment period; ${ }^{19,21,22}$ two studies administered $100 \mathrm{mg}$ DIC (one tablet, twice daily) during the whole treatment period; ${ }^{20,23}$ and in one study $150 \mathrm{mg}$ DIC (two tablets, three times daily) was administered throughout the whole treatment period. ${ }^{24}$ Only one study contained a pure placebo group in addition to OEC and DIC, ${ }^{24}$ the other five trials were solely actively controlled.

Subjects were assigned randomly to receive three times daily either one DIC tablet and two tablets of an indistinguishable placebo, or two tablets of Wobenzym and one tablet of placebo following a double-dummy approach. All interventions were identical in the total number of tablets and appearance. The random assignment of subjects to treatment 
groups was achieved through the use of computer-generated randomization lists in continuous recruitment order.

Besides the study medications and the continued use of daily low-dose aspirin for cardiovascular prophylaxis, no other antiphlogistic or analgesic therapies were permitted throughout the studies. When necessary, patients were allowed to self-medicate with acetaminophen (500 mg per tablet, up to 2,000 mg per day); however, they had to stop this rescue medication 24 hours prior to each scheduled examination. Treatments were given daily for a planned duration of 3 weeks in three studies, ${ }^{19,21,22} 6$ weeks in two, ${ }^{20,23}$ and 12 weeks in one study. ${ }^{24}$

\section{Efficacy outcomes}

In all six studies, primary efficacy analyses were based on the self-assessment of pain and functionality of the affected knee joint using the LAFI. Secondary efficacy analyses addressed self-assessments of knee pain intensity at rest (PIR) and pain intensity in motion (PIM).

\section{Safety assessments}

Drug safety was assessed by analyses of occurrence, nature, severity, and relevance of AEs, as well as drug-related treatment-emergent AEs (TEAEs), that occurred during the studies, either recorded in patient diaries or communicated directly to study personnel. In addition, vital signs (resting systolic and diastolic blood pressure, heart rate, and body temperature) were recorded and blood samples for routine laboratory measurements taken at baseline and end-of-study visits.

\section{Data collection and IPD extraction}

After careful evaluation of the study materials collected with respect to their completeness and quality, the original (raw) data of each study were extracted by two independent clinical research associates (blinded for study treatment) using a uniform case-report form specifically developed for this analysis. During this process, all randomized patients with a case-report form containing at least one postbaseline measure were registered, even those lost to follow-up and/or excluded from the published analyses of the original trials (modified intent-to-treat [ITT] approach). After this transfer, both data sets for each study were independently captured electronically using an optical character-recognition program for automated data capture from filled forms ${ }^{26}$ and compared to exclude any extraction inconsistencies to guarantee $100 \%$ concordance with the original study data. Finally, consolidated databases of all six trials were merged together in a single database, which built the basis for the meta-analysis.

\section{Efficacy assessments}

Efficacy assessments were performed on the basis of patientreported outcomes available in all studies identified for the LAFI, PIR, and PIM. The LAFI is an internationally used validated patient questionnaire for the self-assessment of OA-related joint pain and functional disability in daily life recommended by the US Food and Drug Administration and the European Medicines Agency. ${ }^{27,28}$ It provides an estimate of the pain intensity associated with the affected joint, the maximum distance walked, and activities of daily living, and is reported as a total (index) score ranging from 0 (no impairment) to 24 (worst functional impairment possible). ${ }^{29}$ PIR and PIM, based on the OA-related knee-joint pain intensity for both conditions, were rated by patients on the basis of the $\mathrm{NRS}_{11}$.

\section{Safety and tolerability measures}

Safety assessments consisted of monitoring all TEAEs, collected via spontaneous reports and patient visits. In the original studies, TEAEs were collected through both direct questioning by the physicians and spontaneous patient reports, and were recorded at each visit. After data extraction, all TEAEs were uniformly encoded with the Medical Dictionary for Regulatory Activities (version 17.1) ${ }^{30}$ and evaluated for severity and relationship to study medication.

\section{Laboratory measures}

Laboratory analyses focused on treatment-related changes of parameters known to be directly or indirectly affected by NSAIDs like DIC. Parameters of primary interest were hemoglobin, hematocrit, and erythrocyte count, as well as the key hepatic enzymes AST, ALT, and GGT.

\section{Statistical analysis}

The aim of this study was to evaluate the efficacy and safety/ tolerability of OEC vs DIC for adult patients suffering from OA of the knee. Primary efficacy criteria for these comparisons were the treatment contrasts for LAFI improvement at study end compared to baseline. The primary efficacy end point was absolute LAFI change vs baseline. Due to the recommendations of Bellamy et al and Tubach et al, 3 points on the raw LAFI scale were formally defined as a noninferiority margin. ${ }^{31,32}$ Secondary efficacy parameters included 1) the proportion of LAFI responders (ie, patients experiencing a clinically relevant 
LAFI improvement, defined as either a relative and/or absolute improvement $\geq 50 \% / \geq 3$ index points) at study end vs baseline, 2) absolute and relative (percentage vs baseline) change in PIR and PIM, 3) the proportion of patients with PIM relief equal to or above the minimal clinically important difference (MCID) of 2 points on the $\mathrm{NRS}_{11}$, ${ }^{32}$ and 4) percentage of those patients reporting a $\geq 30$ and $\geq 50 \%$ improvement vs baseline.

The primary safety end point was the percentage of patients with TEAEs. Secondary safety/tolerability parameters covered the percentages of patients with TEAE-related study discontinuations and the spectrum and characteristics of the TEAEs reported.

The primary end point of the laboratory analyses was the proportion of patients within both treatment groups who presented with a combined decrease in hemoglobin, hematocrit, and erythrocyte count (taken as indirect measures for treatment-related blood loss via subclinical lesions of the GI mucosa), as well as an increase in all three hepatic key enzymes at study end (taken as an indicator for drug-related hepatic reactions), irrespective of the dimension. Secondary end points evaluated absolute changes at study end vs baseline and the percentage of patients with any change for each individual laboratory parameter.

Efficacy analyses were performed primarily for the ITT population, which consisted of all randomized patients who took at least one dose of study medication and who had at least one postbaseline/postdose efficacy measure (modified ITT approach). For the primary efficacy end point, additional per protocol (PP) analyses were performed to get a more conservative look on the comparability of treatment effects. Safety analyses based on the safety population, which consisted of all randomized patients who took at least one dose of study medication, and laboratory evaluations were done for all randomized patients with at least one baseline blood sample (laboratory population).

Due to the exploratory design of this IPD meta-analysis, no formal sample-size estimations were performed. Linear interpolation was used to impute intermittent missing scores and the last-observation-carried-forward method to impute missing scores after early discontinuation. ${ }^{33-35}$ The corresponding last-observation-carried-forward data set built the basis for all primary and secondary end-point analyses. For continuous variables, descriptive statistics were summarized by the number of patients, the mean, standard deviation (SD), $95 \%$ confidence interval $(95 \% \mathrm{CI})$ of the mean, median, and range. For categorical and ordinal variables, data were summarized by frequency and percentage (\%) of participants in each category; where appropriate, $95 \%$ CIs were added.
All efficacy, safety, and tolerability analyses were done in the form of a one-stage approach for the whole patient sample, which allowed adjustment for any heterogeneity among the included studies. For between-groups comparisons of continuous/categorical variables, Student $t$-tests/Pearson's $\chi^{2}$ tests were used. For within-group (eg, before and after) comparisons, paired-sample $t$-tests were performed. All statistical tests were carried out using a two-sided significance level of 0.05 and were based on a Holm-Bonferroni approach to counteract the problem of multiple comparisons. ${ }^{35,36}$

An additional two-stage approach was performed as formal meta-analysis for the primary efficacy end point, and both efficacy populations were evaluated (ITT and PP) to quantify the amount of heterogeneity between included studies. Mean differences were based on analyses of covariance (outcome measures adjusted for baseline LAFI scores): equality 0 , superiority $<0$, inferiority $>1$ ). Tests for quantitative heterogeneity were performed using standard $\chi^{2}$ and $I^{2}$ statistics. Qualitative interaction was evaluated by the Gail-Simon test. ${ }^{37}$ If there was no evidence for a qualitative interaction ( $P \geq 0.2$ ), a fixed-effect model according to Hedges and Olkin was used ${ }^{38}$ otherwise $(P<0.2)$, a random-effect model was used to estimate between-study variance according to DerSimonian and Laird. ${ }^{39,40}$

All assessments and analyses were performed blinded without information on treatment-group membership or study medications. Treatment codes were only released at the end of the statistical process and after completion of all analyses to evaluate any between-group differences.

\section{Evaluation of study selection/ publication bias}

Possible publication bias was evaluated with the funnel-plot approach - introduced by Light and Pillemer and extensively discussed by Egger et al - on basis of the treatment effects for the primary end point analysis (mean LAFI difference) and the corresponding standard errors calculated during the two-stage approach. ${ }^{41-43}$

\section{Ethics}

Data from positively identified studies were only included in this IPD meta-analysis if the original studies were conducted in accordance with the principles of the Declaration of Helsinki and Good Clinical Practice, conformed to relevant national and local ethical and regulatory requirements valid at the time of the study, had been approved by an independent ethics committee prior to beginning, and informed consent was obtained from all study patients. 
This meta-analysis was evaluated and approved by the managing boards of the DGS and the DSL, and registered in the German pain study registry (Gesellschaft für Schmerzmedizin 2015-0005-01) and in the European Network of Centres for Pharmacoepidemiology and Pharmacovigilance (ENcEPP) electronic study registry of the European Medicines Agency (ENcEPP/SDPP/12247).

\section{Results}

\section{Study population}

Overall, those six studies identified and selected for this IPD meta-analysis randomized 774 patients (see Table 1 and patient disposition in Figure 1). A total of 759 patients received study medication ( $n=375$ with OEC and $n=384$ with DIC) and accumulated postbaseline data, qualifying for being included in the safety population. Of those, 536 (70.6\%) completed the whole observation period: 270 (72\%) with OEC and 266 (69.3\%) with DIC. Within the safetyanalysis population, 697 patients $(90.1 \%$ of those randomized) - of whom 348 had been treated with OEC and 349 with DIC - recorded at least one postbaseline efficacy measure, qualifying for inclusion into the modified ITT population for the efficacy analysis. A total of 523 patients $(67.6 \%$ of those randomized and $75.2 \%$ of ITT) formed the PP population ( $\mathrm{n}=265$ with OEC, $\mathrm{n}=258$ with DIC), and 500 patients (64.6\%) presented with evaluable laboratory-data recordings and were aggregated as the laboratory-analysis population ( $n=247$ with OEC, $n=253$ with DIC).

\section{Baseline demographic and clinical characteristics}

Main demographic and baseline characteristics for the safety population are shown in Table 2. Despite some heterogeneity between studies, baseline parameters were well balanced among both treatment groups, with only minor (and insignificant) between-group differences. Mean \pm SD age of the patients was $60.9 \pm 10.2$ years. Patient age varied between 52 and 63.5 years, and with 127 patients $(18.2 \%)$, nearly a fifth were older than 70 years. Twothirds of patients $(n=477,68.4 \%)$ were female. Average \pm SD LAFI score at baseline was $12.7 \pm 2.3$, and ranged from 7 to 21 in the OEC group and from 6 to 21 in the DIC group. Average \pm SD PIR and PIM were $3.9 \pm 2.3$ and $6.5 \pm 1.8 \mathrm{NRS}_{11}$. Corresponding percentages of patients with PIR/PIM scores $\leq 3 \mathrm{NRS}_{11}$ (indicative for "minor"/"mild" pain) were $325(41.5 \%) / 35(4.5 \%)$, and comparable for both treatment groups.

\section{Efficacy analysis}

\section{Primary end point}

The LAFI improved significantly within both treatment groups at study end vs baseline (Table 3 ). With OEC, average \pm SD LAFI scores improved from 12.6 \pm 2.4 at baseline to $9.1 \pm 3.9$ at study end $(P<0.001)$ and with DIC from $12.7 \pm 2.4$ to $9.1 \pm 4.2(P<0.001)$. Absolute $\left(\mathrm{NRS}_{11}\right)$ /relative (percentage) differences at study end vs baseline were $-3.5 \pm 4.2 /-27.8 \pm 30.8$ for OEC, comparable to those for DIC, with $-3.6 \pm 4.3 /-28.3 \pm 32.1$ (not significant for either parameter). With Cohen's $d$ of 0.9 for OEC and 0.88 for DIC, corresponding treatment-effect sizes were large (ie, $>0.8$ ).

Forest plots in Figure 2 for the ITT and PP populations show only minor and statistically insignificant differences for LAFI scores at study end ( $P=0.1379 / 0.2731$ for ITT/PP analysis). Based on a fixed-effect model, mean (95\% CI) differences for the ITT population were $0.3125(-0.1003$ to $0.7253)$ and 0.2662 for PP ( -0.2098 to 0.7422$)$. Calculated between-group differences were small and clinically irrelevant, as they were far below the predefined noninferiority margins of \pm 3 , and calculated CIs excluded any relevant between-group differences (ITT 0.7253, PP 0.7422), thus confirming noninferiority up to a very narrow range.

\section{Secondary end points}

In total, $76.4 \%$ of patients treated with OEC $(n=266)$ and $76.8 \%$ of those treated with DIC $(n=268)$ presented with an LAFI improvement vs baseline (Table 3). Proportions of patients reporting distinct LAFI response rates vs baseline were comparable among both treatment groups (see Figure 3). A $\geq 30 \%$ response was seen for $138 / 143 \mathrm{OEC} /$ DIC patients (39.7\%/41\%): 82/84 (23.6/24.1\%) reported $\geq 50 \%$ response and $38 / 41(10.9 \% / 11.7 \%) \geq 70 \%$ response. In parallel, the proportion of patients with LAFI scores $\leq 7$, indicating only "minor"/“mild" OA impairment increased with OEC to $115(33 \%, P<0.001)$ and for those treated with DIC to $117(33.5 \%, P<0.001)$.

Regression analyses of the before-and-after development of LAFI scores for both treatment collectives and ITT patients (see Figure 4) revealed for both treatments a proportional improvement: largest treatment effects were observed for patients with highest OA burden (LAFI scores) at baseline, and treatment effects decreased toward those patients with minor impairments. Regression lines for the before-and-after LAFI scores of patients treated with OEC and DIC were almost congruent, as were the corresponding regression parameters. 


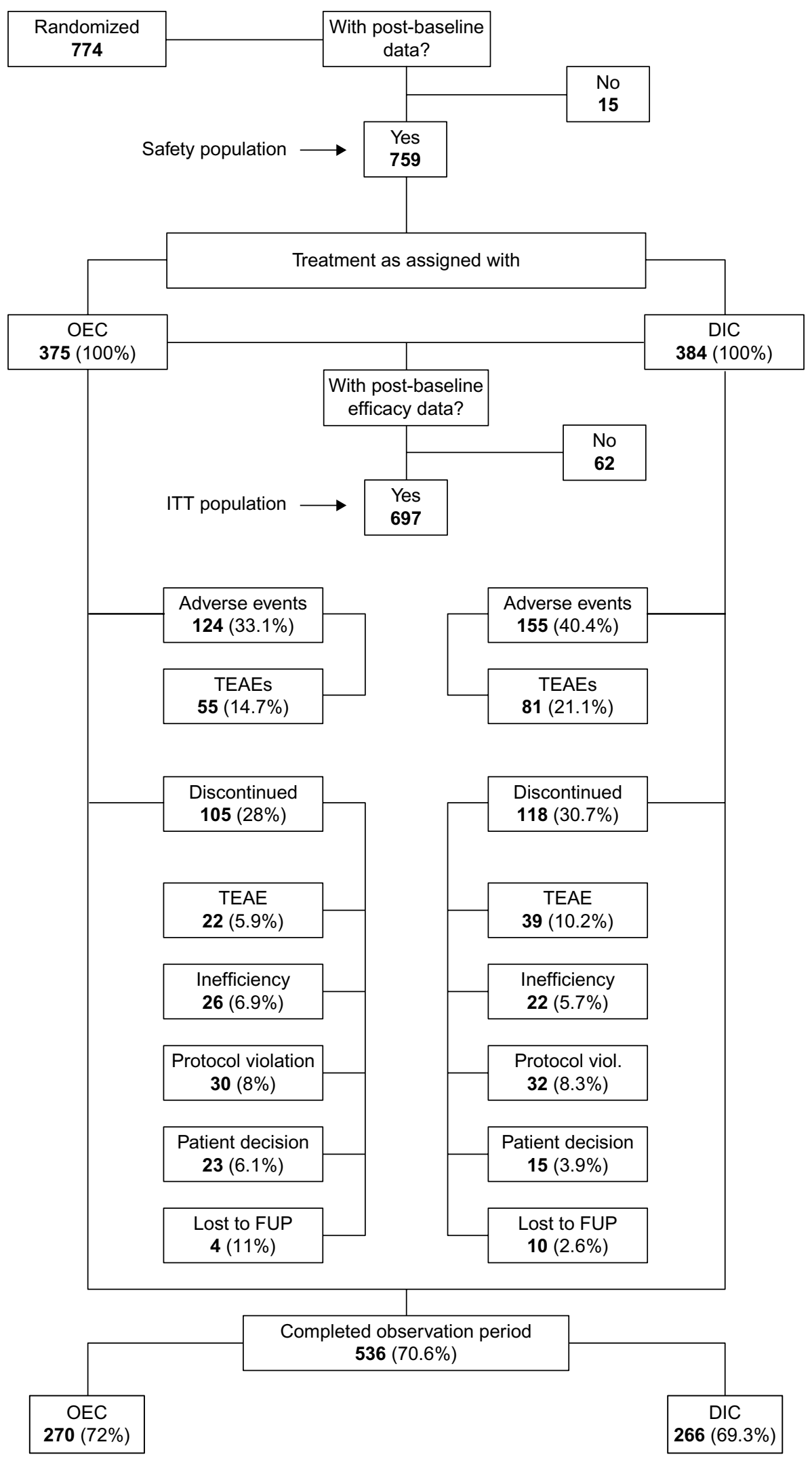

Figure I Patient disposition.

Abbreviations: OEC, oral enzyme combination; DIC, diclofenac; TEAEs, treatment-emergent adverse events; FUP, follow-up. 
Table 2 Patient demographic and baseline characteristics

\begin{tabular}{|c|c|c|c|c|}
\hline Safety population & All $(n=759)$ & OEC $(n=375)$ & DIC $(n=384)$ & Significance (OEC/DIC) \\
\hline \multicolumn{5}{|l|}{ Demographic data } \\
\hline Age (years), mean (SD) & $60.9(10.2)$ & $60.5(10.2)$ & $61.2(10.4)$ & NS \\
\hline Patients $\geq 70$ years, $\mathrm{n}(\%)$ & $138(18.2)$ & $68(18.1)$ & $70(18.2)$ & NS \\
\hline Female sex, $\mathrm{n}(\%)$ & $519(68.4)$ & $252(67.2)$ & $267(69.5)$ & NS \\
\hline Body weight $(\mathrm{kg})$, mean $(\mathrm{SD})$ & $83(18.2)$ & $82.8(19.1)$ & $83.2(17.6)$ & NS \\
\hline Height $(\mathrm{cm})$, mean $(\mathrm{SD})$ & $164.8(10.3)$ & $165.3(10.7)$ & $164.3(10.1)$ & NS \\
\hline BMI $\left(\mathrm{kg} / \mathrm{m}^{2}\right)$, mean $(\mathrm{SD})$ & $30.6(6.2)$ & $30.3(6.5)$ & $30.8(6)$ & NS \\
\hline \multicolumn{5}{|l|}{ Baseline characteristics } \\
\hline LAFI, mean (SD) & $12.7(2.3)$ & $12.6(2.4)$ & $12.7(2.4)$ & NS \\
\hline Patients with LAFI $\leq 7, \mathrm{n}(\%)$ & $8(I .1)$ & $4(1.1)$ & $4(1)$ & NS \\
\hline $\operatorname{PIR}\left(\mathrm{NRS}_{11}\right)$, mean (SD) & $3.9(2.3)$ & $3.9(2.3)$ & $3.9(2.2)$ & NS \\
\hline Patients with PIR $\leq 3\left(\mathrm{NRS}_{11}\right), \mathrm{n}(\%)$ & $353(46.5)$ & $174(46.4)$ & $179(46.6)$ & NS \\
\hline $\operatorname{PIM}\left(\mathrm{NRS}_{\mid 1}\right)$, mean $(\mathrm{SD})$ & $6.5(1.8)$ & $6.4(1.9)$ & $6.6(1.8)$ & NS \\
\hline Patients with PIM $\leq 3$ at baseline $\left(\mathrm{NRS}_{11}\right), \mathrm{n}(\%)$ & $38(5)$ & $18(4.8)$ & $20(5.2)$ & NS \\
\hline
\end{tabular}

Note: Data given for the whole safety population (All) and both treatment groups (OEC vs DIC).

Abbreviations: OEC, oral enzyme combination; DIC, diclofenac; SD, standard deviation; NS, not significant; BMI, body mass index; LAFI, Lequesne algofunctional index; PIR, pain intensity at rest; $\mathrm{NRS}_{\text {II }}$, II-point numeric rating scale; PIM, pain intensity on movement.

Table 3 Primary efficacy end-point parameters

\begin{tabular}{|c|c|c|c|c|}
\hline Intent-to-treat population (LOCF data set) & All $(n=697)$ & OEC $(n=348)$ & DIC $(n=349)$ & Significance (OEC/DIC) \\
\hline \multicolumn{5}{|l|}{ LAFI } \\
\hline At baseline, mean (SD) & $12.7(2.3)$ & $12.6(2.4)$ & $12.7(2.4)$ & NS \\
\hline At end of treatment, mean (SD) & $9.1(4)$ & $9.1(3.9)$ & $9.1(4.2)$ & NS \\
\hline Absolute difference, mean (SD) & $-3.6(4.1)$ & $-3.5(4.2)$ & $-3.6(4.3)$ & NS \\
\hline Relative difference (percentage), mean (SD) & $-28.1(31.9)$ & $-27.8(30.8)$ & $-28.3(32.1)$ & NS \\
\hline Effect size & 0.88 & 0.9 & 0.88 & NS \\
\hline Significance & - & $<0.001$ & $<0.001$ & \\
\hline$\leq 7$ at baseline, $n(\%)$ & $7(1)$ & $3(0.9)$ & $4(1.1)$ & NS \\
\hline$\leq 7$ at end of treatment; $n$ (\%) & $232(33.3)$ & $115(33)$ & $117(33.5)$ & NS \\
\hline Difference, absolute (relative), n (\%) & $225(32.3)$ & $112(3 \mid)$ & $113(32.1)$ & NS \\
\hline Significance & - & $<0.001$ & $<0.001$ & \\
\hline Relief $\geq 30 \%, \mathrm{n}(\%)$ & $28 I(40.3)$ & $138(39.7)$ & $143(4 \mid)$ & NS \\
\hline Relief $\geq 50 \%, \mathrm{n}(\%)$ & $166(23.8)$ & $82(23.6)$ & $84(24.1)$ & NS \\
\hline Relief $\geq 3$ points, $n(\%)$ & $377(54.1)$ & $185(53.2)$ & $192(55)$ & NS \\
\hline
\end{tabular}

Notes: Data show absolute LAFI scores at baseline vs end of treatment, absolute and relative (ie, percentage) changes vs baseline, and proportion of patients with moderate LAFI scores or less (ie, $\leq 7$ ) at baseline vs study end, as well as a responder analysis with respect to the patients reporting a relative LAFI change vs baseline of $\geq 30 \%, \geq 50 \%$, or $\geq 3 \mathrm{LAFI}$ index points (minimal clinically important difference) at study end. Data given for the whole intent-to-treat population (All) and both treatment groups (OEC vs DIC). Abbreviations: LOCF, last observation carried forward; OEC, oral enzyme combination; DIC, diclofenac; LAFI, Lequesne algofunctional index; SD, standard deviation; NS, not significant.

Proportions of patients presenting with a clinically significant LAFI response at study end (ie, those with an improvement equal to or greater than the corresponding MCID of 3 $\mathrm{NRS}_{11}$ points in combination with $\geq 50 \%$ relief vs baseline; see Table 4) were comparable for OEC $(n=81,23.3 \%)$ and DIC ( $\mathrm{n}=83,23.8 \%$, odds ratio [OR 0.97]; $P=0.954$ ).

OA-related knee-joint PIR and PIM improved significantly with both treatments at study end vs baseline (Table 4 and Figure 5). Average \pm SD NRS ${ }_{11}$ scores for PIR improved for OEC/DIC from 3.9 $\pm 2.3 / 3.9 \pm 2.2$ at baseline to $2.3 \pm 2.4 / 2.3 \pm 2.2$ at study end (absolute change $-1.6 \pm 2.3 /-$ $1.6 \pm 2.2 \mathrm{NRS}_{11}$, relative change $-41 \% \pm 60.5 \% /-41 \% \pm 62.8 \%$, effect size $0.68 / 0.65$; vs baseline $P<0.001$ for both groups).
Proportions of patients with pain-intensity scores $\leq 3 \mathrm{NRS}_{11}$ increased with OEC/DIC from 46\%/47.3\% $(n=160 / 165)$ at baseline to $71.8 \% / 71.9 \%(\mathrm{n}=250 / 251)$ at study end ( $P<0.001$ for both treatments), and corresponding $\geq 30 \%$ and $\geq 50 \%$ response rates were at $57.5 \% / 57.9 \%(n=200 / 202)$ and $39.9 \% / 40.1 \%(n=139 / 140)$, comparable among both treatment groups. PIM scores improved from OEC/DIC $6.4 \pm 1.9 / 6.6 \pm 1.8$ at baseline to $3.8 \pm 2.7 / 3.9 \pm 2.5$ at study end (absolute change $-2.6 \pm 2.6 /-2.7 \pm 2.5 \mathrm{NRS}_{11}$, relative change $-40.6 \% \pm 40.2 \% /-40.9 \% \pm 40.6 \%$, effect size 1.01 for both; vs baseline $P<0.001$ for both treatments). Percentage with PIM NRS $_{11}$ scores $\leq 3$ increased from OEC/DIC 4.9\%/5.2\% $(n=17 / 18)$ at baseline to $47.7 \% / 48.4 \%(n=166 / 169)$ at study 
A

Study/subgroup

Herrera $^{22} 1998$

Klein and Kullich ${ }^{21} 2000$

Singer et al ${ }^{19} 2001$

Roth and Stauder ${ }^{23} 2001$

Akhtar et al ${ }^{20} 2004$

Bolten et al ${ }^{24} 2014$

Fixed effects

Hedges-Olkin ${ }^{38}$

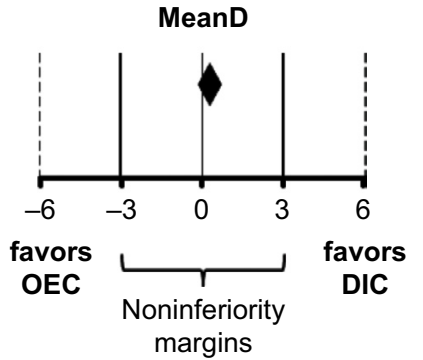

Weight MeanD

$29.7 \quad 0.2309$

$14 \quad-0.2761$

4.8

0.4002

1.1044

$-0.1777$

0.2048

MeanD

0.3125

$(-0.1003$ to 0.7253$)$
Significance

0.5500

0.6239

0.6764

0.0119

0.7618

0.7017

Significance

0.1379

$R^{2}=0.0273(0-0.8656)$

Quantitative interaction: $\chi^{2}=5.1405(d f=5) ; P=0.3390$

Qualitative interaction: Gail-Simon $Q=0.3323 ; P=0.8364$

B Study/subgroup

Herrera $^{22} 1998$

Klein and Kullich ${ }^{21} 2000$

Singer et al ${ }^{19} 2001$

Roth and Stauder ${ }^{23} 2001$

Akhtar et $\mathrm{al}^{20} 2004$

Bolten et $\mathrm{al}^{24} 2014$

Study/subgroup

Hedges-Olkin ${ }^{38}$

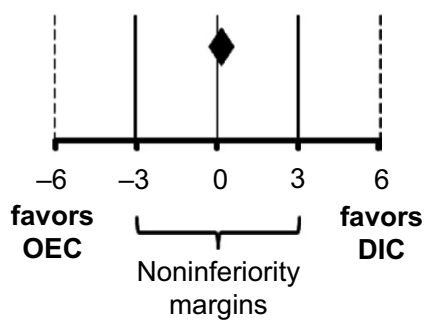

$r^{2}=0.1217(0-0.8822)$

Quantitative interaction: $\chi^{2}=5.6927(d f=5) ; P=0.3373$

Qualitative interaction: Gail-Simon $Q=1.3820 ; P=0.5772$

$\begin{array}{rrrr}\text { Weight } & \text { MeanD } & 95 \% \text { Cl } & \text { Significance } \\ 31.7 & 0.2191 & (-0.6260 \text { to } 1.0642) & 0.6114 \\ 15.5 & -0.4114 & (-1.6186 \text { to } 0.7958) & 0.5042 \\ 5.5 & 0.2789 & (-1.7470 \text { to } 2.3048) & 0.7873 \\ 20.1 & 1.1573 & (0.0962 \text { to } 2.2184) & 0.0325 \\ 8.7 & -0.7982 & (-2.4154 \text { to } 0.8190) & 0.3333 \\ 18.4 & 0.4426 & (-0.6667 \text { to } 1.5519) & 0.4342\end{array}$

Weight

MeanD

$95 \% \mathrm{Cl}$

Significance

$0.2662 \quad(-0.2 .98$ to 0.7422$)$

0.2731

Figure 2 OEC vs DIC on LAFI score (primary efficacy end point) for six randomized controlled trials.

Notes: Comparison (ANCOVA) of efficacy (effect size: mean difference, LOCF data set) for intent-to-treat (A) and per protocol (B) populations.

Abbreviations: OEC, oral enzyme combination; DIC, diclofenac; LAFI, Lequesne algofunctional index; ANCOVA, analysis of covariance; LOCF, last observation carried forward; $\mathrm{Cl}$, confidence interval; $\mathrm{D}$, difference. 
A

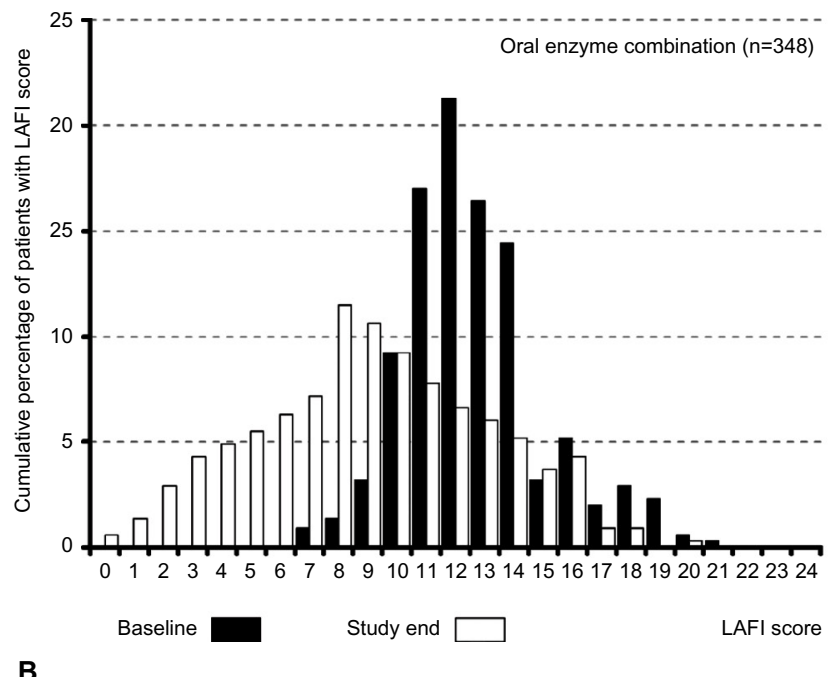

B

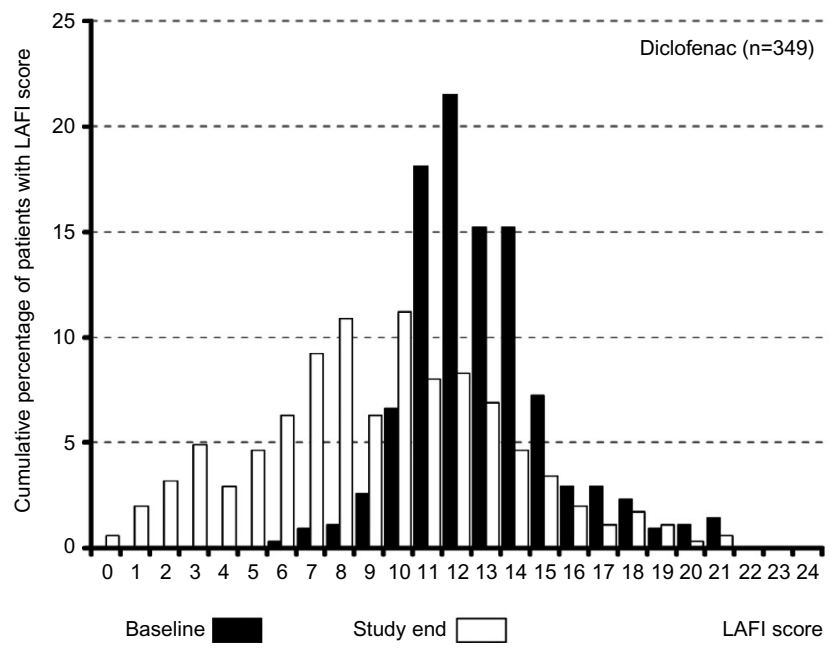

C

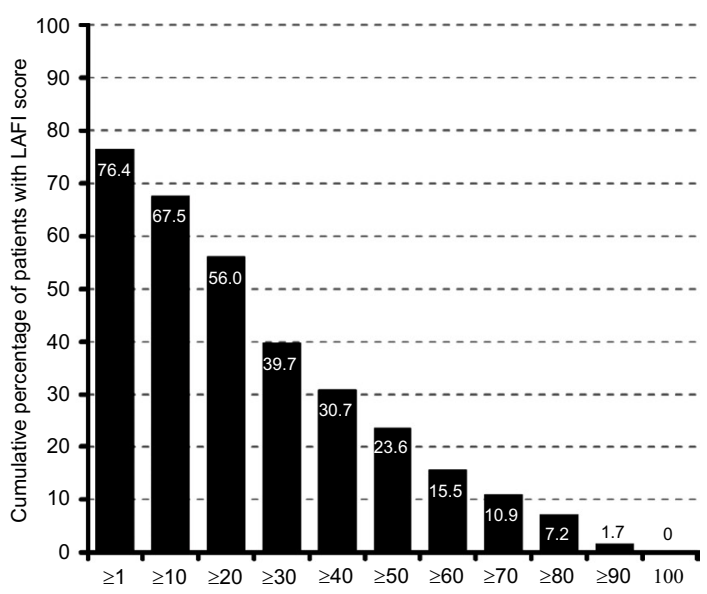

Percentage response at study end (\%vs baseline)

D

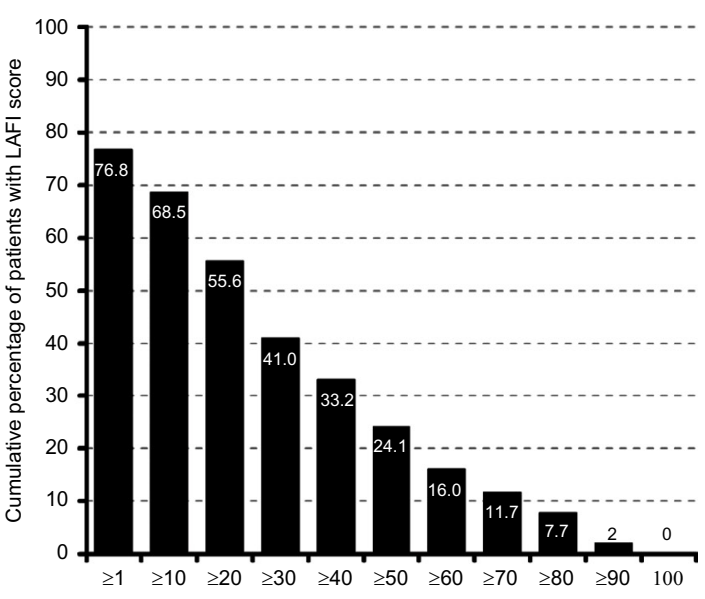

Percentage response at study end (\%vs baseline)

Figure 3 Lequesne algofunctional index (LAFI) scores.

Notes: Scores at baseline (black columns) vs study end (white columns, A,B) and corresponding relative relief/improvement rates (C,D) for the oral enzyme combination $(\mathbf{A}, \mathbf{C})$ vs diclofenac (B,D). Data given for the intent-to-treat population.

end $(P<0.001$ for both), and corresponding $\geq 30 \%$ and $\geq 50 \%$ response rates were identical: $56.6 \% / 57 \%(n=197 / 199)$ and $34.2 \% / 35.5 \%(n=119 / 124)$.

\section{Safety analysis}

As shown in Figure 6 and Table 5, a total of 655 AEs were registered, of which 223 were classified as TEAEs related to OEC $(n=90)$ or DIC $(n=133)$. Within the safety population, significantly fewer patients treated with OEC $(n=55$, $14.7 \%)$ vs DIC ( $n=81,21.1 \%)$ met the primary safety end point and reported at least one TEAE (OR 0.64, 95\% CI $0.44-0.94 ; P=0.021)$. Two or more TEAEs were reported with OEC by $5.9 \%(n=22)$ vs $10.4 \%(n=40)$ with DIC (OR 0.54 , 95\% CI $0.31-0.92 ; P=0.022)$, and TEAE-related treatment discontinuations were seen in $5.9 \%$ of patients treated with OEC ( $n=22)$ vs $10.2 \%$ with DIC $(n=39$, OR $0.55,95 \%$ CI $0.32-0.95 ; P=0.03)$. The detailed analysis shown in Table 5 revealed that the majority of patients with TEAEs $(15.3 \%$, $\mathrm{n}=116$ ) reported events associated with the GI system (overall 162 TEAEs). In total, 72 DIC vs 44 OEC patients (18.8\% vs $11.7 \%$ ) reported at least one TEAE affecting the GI system $(P=0.007)$. Abdominal discomfort as reportable single TEAE was the most frequently documented drug-related AE, noted with OEC/DIC in 3.2\%/8.6\% ( $\mathrm{n}=12 / 33, P=0.002)$, followed by diarrhea in $5.6 \% / 5.2 \%(n=21 / 20$, not significant $)$ and dyspepsia in $1.3 \% / 3.9 \%(n=5 / 15, p=0.027)$. In 12 vs three DIC vs OEC patients (3.1\% vs $0.8 \%)$ laboratory parameters were conspicuous $(P=0.021)$, and six vs no patients presented with cardiovascular TEAEs $(P=0.015)$. Overall, the majority of TEAEs were classified as mild $(\mathrm{n}=115,51.6 \%)$ or moderate intensity $(n=95,42.6 \%)$, and only in $5.8 \%(n=13)$ as severe. In all cases, TEAEs recovered completely, without any countermeasures $(n=123)$, after treatment discontinuation $(n=91)$, or with the help of a supportive drug treatment $(n=9)$. 
Table 4 Secondary efficacy end-point analysis

\begin{tabular}{|c|c|c|c|c|}
\hline Intent-to-treat population (LOCF data set) & All $(n=697)$ & OEC $(n=348)$ & DIC $(n=349)$ & Significance (OEC/DIC) \\
\hline \multicolumn{5}{|l|}{ Pain intensity at rest (PIR) } \\
\hline At baseline $\left(\mathrm{NRS}_{11}\right)$, mean (SD) & $3.9(2.3)$ & $3.9(2.3)$ & $3.9(2.2)$ & NS \\
\hline At end of treatment $\left(\mathrm{NRS}_{11}\right)$, mean (SD) & $2.4(2.4)$ & $2.3(2.4)$ & $2.3(2.2)$ & NS \\
\hline Absolute difference $\left(\mathrm{NRS}_{\mid 1}\right)$, mean (SD) & $-1.5(2.3)$ & $-1.6(2.3)$ & $-1.6(2.2)$ & NS \\
\hline Relative difference (percentage), mean (SD) & $-38.5(59.9)$ & $-4 \mid(60.5)$ & $-4 I(62.8)$ & NS \\
\hline Effect size & 0.64 & 0.68 & 0.65 & NS \\
\hline Significance & - & $<0.001$ & $<0.001$ & \\
\hline$\leq 3\left(\mathrm{NRS}_{11}\right)$ at baseline, $\mathrm{n}(\%)$ & $325(41.5)$ & $160(46)$ & $165(47.3)$ & NS \\
\hline$\leq 3\left(\mathrm{NRS}_{11}\right)$ at end of treatment, $n(\%)$ & $50 \mathrm{I}(64)$ & $250(71.8)$ & $25 I(71.9)$ & NS \\
\hline Difference, absolute (relative) & $176(23)$ & $90(25.9)$ & $86(24.6)$ & NS \\
\hline Significance & - & $<0.001$ & $<0.001$ & \\
\hline Relief $\geq 30 \%, n$ (\%) & $402(57.7)$ & $200(57.5)$ & $202(57.9)$ & NS \\
\hline Relief $\geq 50 \%, n(\%)$ & $279(40)$ & $139(39.9)$ & I $40(40.1)$ & NS \\
\hline Relief $\geq 2\left(\mathrm{NRS}_{11}\right), \mathrm{n}(\%)$ & $376(53.9)$ & $186(53.4)$ & $190(54.4)$ & NS \\
\hline \multicolumn{5}{|l|}{ Pain intensity in motion (PIM) } \\
\hline At baseline $\left(\mathrm{NRS}_{11}\right)$, mean (SD) & $6.5(1.8)$ & $6.4(1.9)$ & $6.6(1.8)$ & NS \\
\hline At end of treatment $\left(\mathrm{NRS}_{11}\right)$, mean (SD) & $4(2.6)$ & $3.8(2.7)$ & $3.9(2.5)$ & NS \\
\hline Absolute difference $\left(\mathrm{NRS}_{\mid 1}\right)$, mean (SD) & $-2.5(2.5)$ & $-2.6(2.6)$ & $-2.7(2.5)$ & NS \\
\hline Relative difference (percentage), mean (SD) & $-38.5(39.4)$ & $-40.6(40.2)$ & $-40.9(40.6)$ & NS \\
\hline Effect size & 0.98 & 1.01 & 1.01 & NS \\
\hline Significance & - & $<0.001$ & $<0.001$ & \\
\hline$\leq 3\left(\mathrm{NRS}_{11}\right)$ at baseline, $\mathrm{n}(\%)$ & $35(5)$ & $17(4.9)$ & $18(5.2)$ & NS \\
\hline$\leq 3\left(\mathrm{NRS}_{\mathrm{II}}\right)$ at end of treatment, $\mathrm{n}(\%)$ & $335(48.1)$ & $166(47.7)$ & $169(48.4)$ & NS \\
\hline Difference, absolute (relative) & $300(39.1)$ & $149(42.8)$ & I5I (43.3) & NS \\
\hline Significance & - & $<0.001$ & $<0.001$ & \\
\hline Relief $\geq 30 \%, n$ (\%) & $396(56.8)$ & $197(56.6)$ & $199(57)$ & NS \\
\hline Relief $\geq 50 \%, n(\%)$ & $243(34.9)$ & $119(34.2)$ & $124(35.5)$ & NS \\
\hline Relief $\geq 2\left(\mathrm{NRS}_{\mid 1}\right), \mathrm{n}(\%)$ & $466(66.9)$ & $231(66.4)$ & $235(67.3)$ & NS \\
\hline
\end{tabular}

Notes: Data show absolute scores for PIR and PIM at baseline vs end of treatment, absolute and relative (percentage) changes vs baseline, and proportion of patients with minor pain intensities (ie, $\leq 3$ ) at baseline vs study end, as well as a responder analysis with respect to patients reporting a relative $\mathrm{PI}$ change vs baseline of $\geq 30 \%$, $\geq 50 \%$, or $\geq 2 \mathrm{NRS}_{11}$ points (minimal clinically important difference) at study end. Data given for the whole intent-to-treat population (All) and both treatment groups (OEC vs DIC). Abbreviations: LOCF, last observation carried forward; OEC, oral enzyme combination; DIC, diclofenac; NRS 1 , II-point numeric rating scale; PI, pain intensity; SD, standard deviation; NS, not significant.

\section{Laboratory analysis}

At first view, evaluation of treatment-related laboratory changes detected only minor differences of the key parameters analyzed in blood samples taken from patients at end of study vs those taken at baseline (see Table 6). Overall, absolute/ relative \pm SD changes vs baseline calculated for hemoglobin $(-0.3 \pm 0.7 /-1.8 \pm 5.3)$, hematocrit $(-0.7 \pm 2.5 /-1.6 \pm 5.8)$, and erythrocyte count $(-0.1 \pm 0.5 /-2.2 \pm 7.2)$ were - equally to those found for AST (1.1 $\pm 11 / 5.8 \pm 23.6)$, ALT (2.8 $\pm 10.4 / 14 \pm 28.4)$, and GGT $(1.8 \pm 11.5 / 8.6 \pm 31.1)$ - neither significant nor clinically relevant. However, between-group analyses revealed significant differences in favor of the enzyme treatment, as both the proportion of patients with any worsening (see Table 6) as well as the degree of change measured at study end vs baseline (see Figure 7) were significantly higher for DIC than OEC. In detail, parameter deteriorations with OEC/DIC were found for hemoglobin in $21.1 \% / 83.4 \%$
( $\mathrm{n}=52 / 211$ patients of the equivalent laboratory population), for hematocrit in $17 \% / 87 \%(n=42 / 220)$, for erythrocyte count in $18.2 \% / 88.5 \%(\mathrm{n}=45 / 22)$, for AST in $28.7 \% / 68.8 \%$ $(\mathrm{n}=71 / 174)$, for ALT in $25.9 \% / 84.2 \%(\mathrm{n}=64 / 213)$, and for GGT in $30 \% / 64.8 \%(\mathrm{n}=74 / 164)(P<0.001$ for each).

Observed absolute/relative changes vs baseline were usually small, but for all laboratory measures evaluated, DIC treatment was followed by a significant worsening, with $P$-values ranging from 0.046 for GGT, 0.043 for AST, and 0.002 for ALT up to $<0.001$ for hemoglobin, hematocrit, and erythrocyte count, in contrast to OEC, which showed no significant changes over time. OEC/DIC-related absolute (relative) changes vs baseline were for AST $-0.4 / 2.5 \mathrm{U} / \mathrm{L}$ $(-2.2 \% / 14.0 \%)$, for ALT $-0.5 / 6.1 \mathrm{U} / \mathrm{L}(-2.5 \% / 30.3 \%)$, and for GGT $-0.9 / 4.5 \mathrm{U} / \mathrm{L}(-4.3 \% / 21.7 \%)$. In total, $218 \mathrm{DIC}$ vs 46 OEC patients ( $86.3 \%$ vs $18.8 \%)$ presented with a combined decrease of hemoglobin, hematocrit, and erythrocyte count 

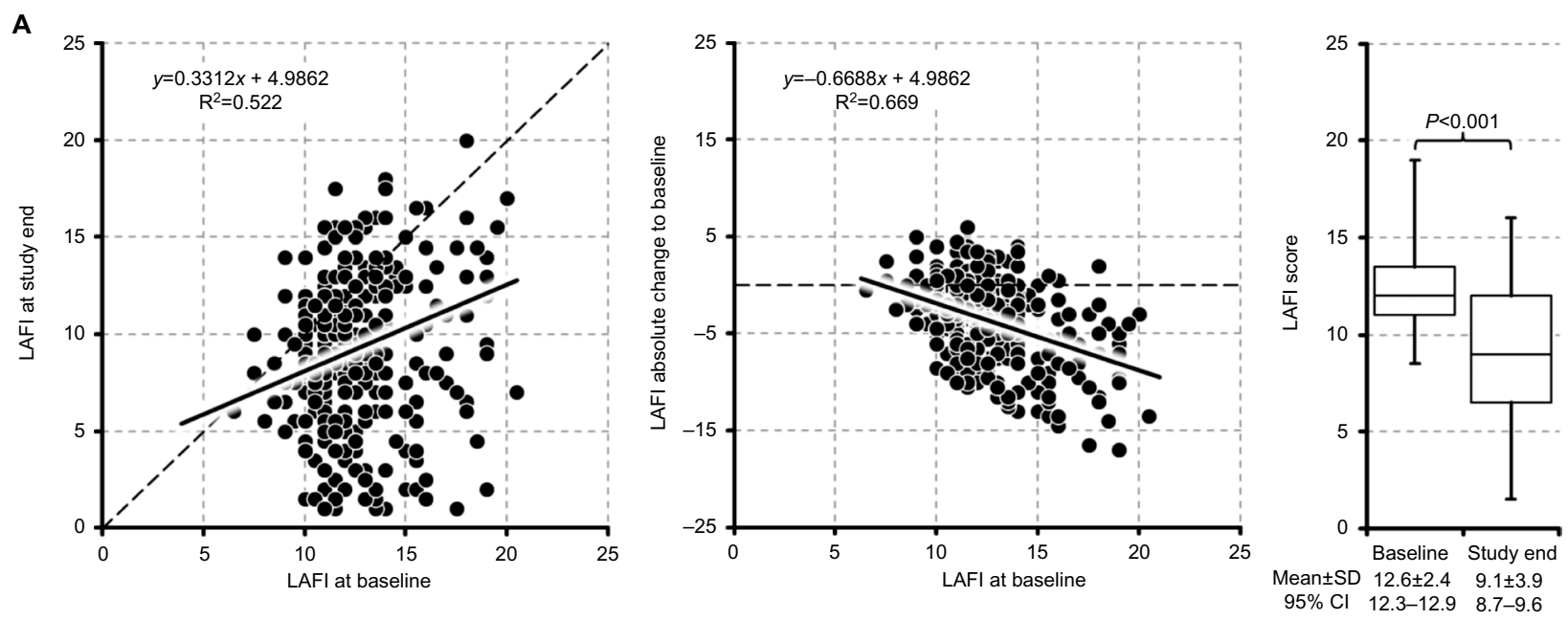

Oral enzyme combination
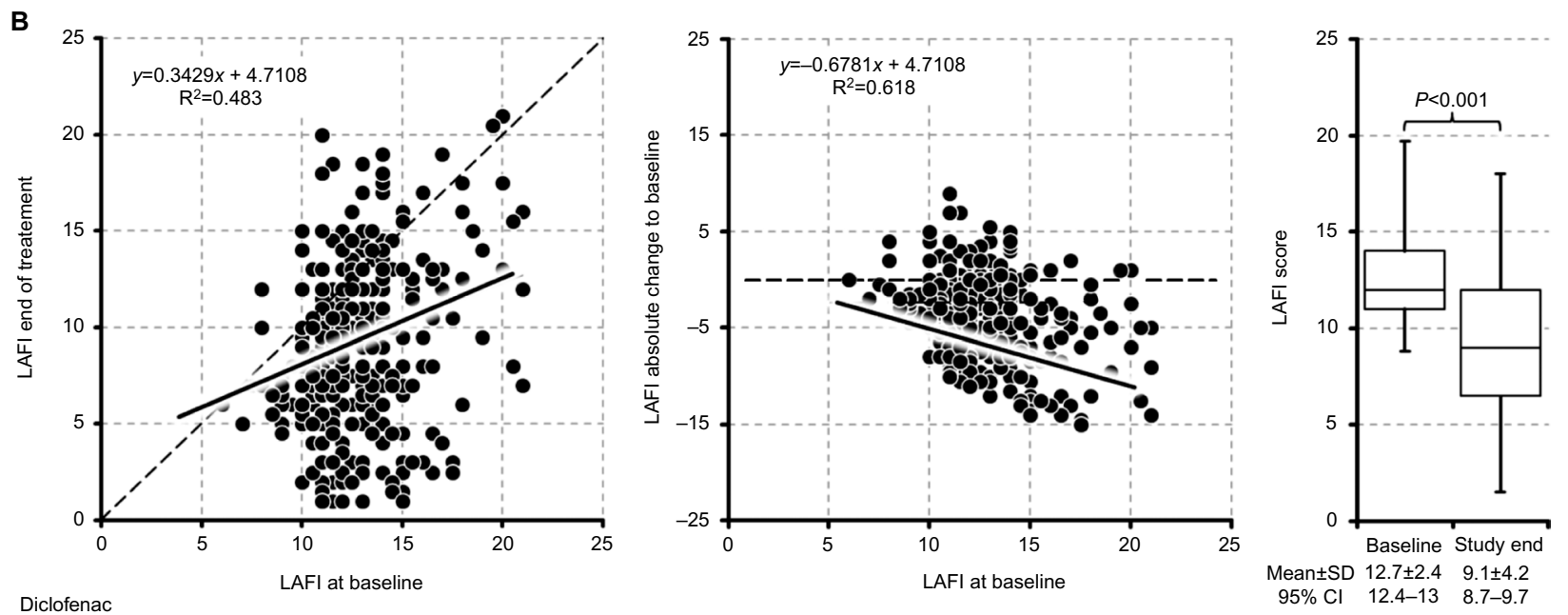

Figure 4 Scatterplots and box-and-whisker plots of the Lequesne algofunctional index (LAFI) scores (primary efficacy endpoint) for the oral enzyme combination (A) and diclofenac (B). Scatterplots base on baseline (X-axis) vs either study end (Y-axis; left panels) LAFI scores or corresponding absolute LAFI changes at study end vs baseline (Y-axis; middle panels). Box-and-whisker plots show LAFI scores at baseline vs end of study. Data are given for the 'intent-to-treat' population (ITT).

Notes: Solid lines are regression lines; dashed lines separate the sectors "improvement" vs "deterioration". (lower right vs upper left sectors for the scatterplots on the left and lower vs upper sectors for the scatterplots in the midst)

Abbreviations: $\mathrm{SD}$, standard deviation; $\mathrm{Cl}$, confidence interval.

(OR 27.22, 95\% CI 16.85-43.97; $P<0.001$ ) and 184 vs 70 (72.6\% vs $28.2 \%$ ), with a combined increase in AST, ALT, and GGT (OR 6.74, 95\% CI 4.56-9.97; $P<0.001$ ). A detectable simultaneous deterioration in any of the aforementioned six laboratory measures (the primary end point of this laboratory analysis) was found for 81 DIC vs 37 OEC patients (32\% vs $15 \%$, OR $2.67,95 \%$ CI $1.73-4.14 ; P<0.001)$.

\section{Publication bias}

No indication of publication bias was found for the studies included in this IPD meta-analysis. As shown with the funnel plot in Figure 8, there was no evidence of bias or positive monotonic relationship between efficacy and sample size ( $P$-value for bias 0.05 ). All six studies included were located within the area defined by the $95 \% \mathrm{CI}$, and varied around the vertical centerline. No traces of unpublished studies were found, despite an extensive search of trial registers and the reference lists of relevant articles ("backward snowballing").

\section{Discussion}

OA is a highly prevalent and restricting disease with significant potential to threaten quality of life. Pain and impairment of physical functioning are the key domains for the overall burden of suffering experienced by patients with OA of the knee. ${ }^{44}$ In addition to physical exercises and lifestyle changes, adequate symptomatic pharmacological management strategies have a beneficial and clinically relevant impact on pain, functional capability in daily life, and overall quality of 

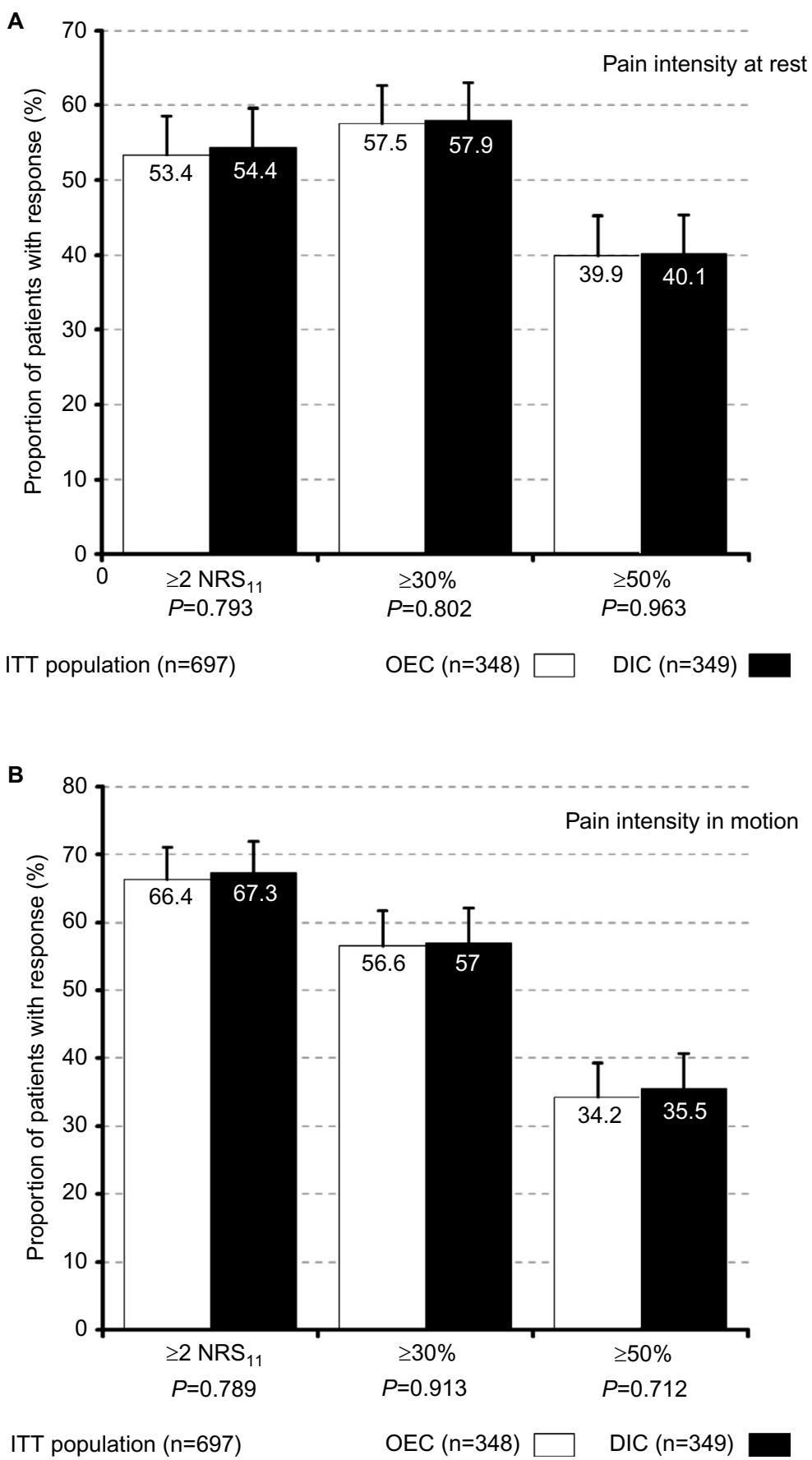

Figure 5 Pain-intensity box plots.

Notes: Proportion ( $+95 \%$ confidence intervals) of patients who recorded either a significant absolute $\left(\geq 2\right.$ NRS $_{11}$ points) or relative change $(\geq 30 \%$, $\geq 50 \%$ improvement) with respect to pain intensity at rest $(\mathbf{A})$ or the pain intensity in motion $(\mathbf{B})$ at study end vs baseline. Data given for the intent-to-treat (ITT) population and patients treated with either the oral enzyme combination (OEC; white columns) or with diclofenac (DIC; black columns).

Abbreviation: $\mathrm{NRS}_{\mid}$, II-point numeric rating scale.

life. ${ }^{45-47}$ Although often pathophysiologically characterized as a primary degenerative disease with intermittent inflammatory flares, chronic low-grade inflammation seems to constitute an important aspect of OA pathology, requiring adequate and ongoing antiphlogistic treatments..$^{48,49}$ NSAIDs are primarily effective in limiting OA-related pain by their capacity to impair inflammation and nociceptive activity through COX2 inhibition; however, they are limited by their potential to cause serious GI, cardiovascular, renal, and allergic side effects, ${ }^{50-54}$ which altogether have evolved into the main life-threatening risk factors of the disease, especially in the elderly, a patient population risk of overall increased mortality. ${ }^{55}$ Due to this, current OA-treatment guidelines specifically recommend using these agents only at the lowest (effective) dose and to avoid 
Table 5 Overall treatment-emergent adverse event (TEAE) experience

\begin{tabular}{|c|c|c|c|c|}
\hline Safety population & All $(n=759), n(\%)$ & OEC (n=375), n (\%) & DIC (n=384), n (\%) & Significance (OEC/DIC), $P$ \\
\hline AEs & 655 & 282 & 373 & - \\
\hline Subjects with AEs & $279(36.8)$ & $124(33.1)$ & $155(40.4)$ & 0.037 \\
\hline TEAEs & 223 & 90 & 133 & - \\
\hline Serious TEAEs & 4 & 0 & 4 & - \\
\hline Subjects with TEAEs & $136(17.9)$ & $55(14.7)$ & $8 I(2 I .1)$ & 0.021 \\
\hline Subjects with $\geq 2$ TEAEs & $62(8.2)$ & $22(5.9)$ & $40(10.4)$ & 0.022 \\
\hline \multicolumn{5}{|l|}{ Most common TEAEs (PT) } \\
\hline Abdominal discomfort & $45(5.9)$ & $12(3.2)$ & $33(8.6)$ & 0.002 \\
\hline Diarrhea & $4 \mathrm{I}(5.4)$ & $21(5.6)$ & $20(5.2)$ & NS \\
\hline Nausea & $20(2.6)$ & $5(1.3)$ & $15(3.9)$ & 0.027 \\
\hline Dyspepsia & $20(2.6)$ & $7(1.9)$ & $13(3.4)$ & NS \\
\hline Headache & $7(0.9)$ & $5(1.3)$ & $2(0.5)$ & NS \\
\hline Vomiting & $4(0.5)$ & $2(0.5)$ & $2(0.5)$ & NS \\
\hline \multicolumn{5}{|l|}{ Affected OCs (TEAEs) } \\
\hline Gastrointestinal system & $162(21.3)$ & $61(16.3)$ & $101(26.3)$ & $<0.001$ \\
\hline Investigations & $15(2)$ & $3(0.8)$ & $12(3.1)$ & 0.021 \\
\hline General disorders & II (I.4) & $4(1.1)$ & $7(1.8)$ & NS \\
\hline Nervous system & $9(1.2)$ & $6(1.6)$ & $3(0.8)$ & NS \\
\hline Musculoskeletal system & $6(0.8)$ & $5(1.3)$ & $\mathrm{I}(0.3)$ & NS \\
\hline Cardiac system & $6(0.8)$ & 0 & $6(1.6)$ & 0.015 \\
\hline Ear and labyrinth disorders & 0 & 0 & 0 & NS \\
\hline \multicolumn{5}{|l|}{ Affected OCs (patients) } \\
\hline Gastrointestinal system & $116(15.3)$ & 44 (II.7) & $72(18.8)$ & 0.007 \\
\hline Investigations & $15(2)$ & $3(0.8)$ & $12(3.1)$ & 0.021 \\
\hline General disorders & II (I.4) & $4(1.1)$ & $7(1.8)$ & NS \\
\hline Nervous system & $7(0.9)$ & $5(1.3)$ & $2(0.5)$ & NS \\
\hline Musculoskeletal system & $5(0.7)$ & $4(1.1)$ & $\mathrm{I}(0.3)$ & NS \\
\hline Cardiac system & $6(0.8)$ & 0 & $6(1.6)$ & 0.015 \\
\hline Ear and labyrinth disorders & 0 & 0 & 0 & NS \\
\hline \multicolumn{5}{|l|}{ Intensity } \\
\hline Mild & $115(5 \mathrm{I} .6)$ & $50(55.6)$ & $65(48.9)$ & - \\
\hline Moderate & $95(42.6)$ & $34(37.8)$ & $61(45.9)$ & NS \\
\hline Severe & $13(5.8)$ & $6(6.7)$ & $7(5.3)$ & - \\
\hline \multicolumn{5}{|l|}{ Countermeasures } \\
\hline None & $123(16.2)$ & $47(12.5)$ & $76(19.8)$ & 0.007 \\
\hline Dosage adjusted & $9(1.2)$ & $\mathrm{I}(0.3)$ & $8(2.1)$ & 0.019 \\
\hline Treatment discontinued (TEAEs) & $91(12)$ & $42(11.2)$ & $49(12.8)$ & NS \\
\hline Treatment discontinued (patients) & $61(8)$ & $22(5.9)$ & $39(10.2)$ & 0.03 \\
\hline \multicolumn{5}{|c|}{ Relationship with study medication } \\
\hline Possible & $148(19.5)$ & $55(14.7)$ & $93(24.2)$ & - \\
\hline Probable & $47(6.2)$ & $20(5.3)$ & $27(7)$ & NS \\
\hline Definite & $28(3.7)$ & $15(4)$ & $13(3.4)$ & - \\
\hline
\end{tabular}

Note: Data given for the whole safety population (All) and both treatment groups (OEC vs DIC).

Abbreviations: AE, adverse event; OEC, oral enzyme combination; DIC, diclofenac; PT, preferred term; NS, not significant; OC, organ class.

long-term treatment whenever possible, de facto confining their use for the episodic treatment of transient OA flares. ${ }^{5,9,56,57}$ While these recommendations are comprehensible from a safety point of view, they disregard not only the aforementioned pathophysiological need for a prolonged antiphlogistic treatment to prevent OA progression but also patients' legitimate claims for treatments that are effective, safe, and well tolerated.

In this meta-analysis of IPD from six individual prospective, double-blind, randomized, DIC-controlled, parallel-group trials in patients with $\mathrm{OA}$ of the knee, treatment with an oral enzyme product containing three natural compounds resulted in a DIC-comparable benefit with respect to both efficacy domains important for OA patients to reduce their overall burden of disease: physical functioning and pain intensity. All six studies included in this IPD meta-analysis had a similar design, and assigned eligible patients randomly to either OEC or DIC treatment for a duration of 3-12 weeks. Treatment groups were equally balanced with regard to patient demographics and OA baseline characteristics. ITT/PP CIs for the treatment-effect difference on the LAFI - the primary efficacy end point of this study - excluded any clinically relevant between-group differences (mean ITT/PP difference 
Table 6 Treatment-related changes in laboratory parameters

\begin{tabular}{|c|c|c|c|c|}
\hline Laboratory population (LOCF data set) & All $(n=500)$ & OEC $(n=247)$ & DIC $(n=253)$ & Significance (OEC/DIC), $P$ \\
\hline \multicolumn{5}{|l|}{ Hemoglobin (g/dL) } \\
\hline Baseline, mean (SD) & I3.9 (I.4) & $13.9(1.3)$ & |3.9 (।.4) & NS \\
\hline End of treatment, mean (SD) & |3.7 (I.4) & $13.9(1.3)$ & I3.4 (I.4) & $<0.001$ \\
\hline Patients with any decrease, $\mathrm{n}$ (\%) & $263(52.6)$ & $52(21.1)$ & $211(83.4)$ & $<0.001$ \\
\hline Absolute difference, mean (SD) & $-0.3(0.7)$ & $0(0.7)$ & $-0.5(0.7)$ & 0.015 \\
\hline Relative difference (percentage), mean (SD) & $-1.8(5.3)$ & $0(5.2)$ & $-3.6(5.4)$ & 0.004 \\
\hline Significance & - & NS & $<0.001$ & \\
\hline \multicolumn{5}{|l|}{ Hematocrit (\%) } \\
\hline Baseline, mean (SD) & $42.5(3.9)$ & $42.5(3.9)$ & $42.4(3.8)$ & NS \\
\hline End of treatment, mean (SD) & $41.8(3.8)$ & $42.5(3.7)$ & $41(3.7)$ & $<0.001$ \\
\hline Patients with any decrease, $\mathrm{n}(\%)$ & $262(52.4)$ & $42(17)$ & $220(87)$ & $<0.001$ \\
\hline Absolute difference, mean (SD) & $-0.7(2.5)$ & $0(2.4)$ & $-1.4(2.4)$ & 0.011 \\
\hline Relative difference (percentage), mean (SD) & $-1.6(5.8)$ & $0(5.8)$ & $-3.3(5.7)$ & 0.005 \\
\hline Significance & - & NS & $<0.001$ & \\
\hline \multicolumn{5}{|l|}{ Erythrocyte count $(1,012 / L)$} \\
\hline Baseline, mean (SD) & $4.6(0.6)$ & $4.6(0.4)$ & $4.6(0.6)$ & NS \\
\hline End of treatment, mean (SD) & $4.5(0.5)$ & $4.7(0.5)$ & $4.3(0.4)$ & $<0.001$ \\
\hline Patients with any decrease, $\mathrm{n}$ (\%) & $269(53.8)$ & $45(18.2)$ & $224(88.5)$ & $<0.001$ \\
\hline Absolute difference, mean (SD) & $-0.1(0.5)$ & $0.1(0.4)$ & $-0.3(0.6)$ & 0.019 \\
\hline Relative difference (percentage), mean (SD) & $-2.2(7.2)$ & $2.2(7.8)$ & $-6.5(7)$ & 0.002 \\
\hline Significance & - & NS & $<0.001$ & \\
\hline \multicolumn{5}{|l|}{ AST (U/L) } \\
\hline Baseline, mean (SD) & $18(10.5)$ & I8.1 (II.7) & $17.9(9.7)$ & NS \\
\hline End of treatment, mean (SD) & 19.1 (14.4) & $17.7(11.4)$ & $20.4(18)$ & 0.026 \\
\hline Patients with any increase, $n(\%)$ & $245(49)$ & $71(28.7)$ & $174(68.8)$ & $<0.001$ \\
\hline Absolute difference, mean (SD) & I.I (II) & $-0.4(5.9)$ & $2.5(15.5)$ & 0.001 \\
\hline Relative difference (percentage), mean (SD) & $5.8(23.6)$ & $-2.2(22.9)$ & $14(30.3)$ & $<0.001$ \\
\hline Significance & - & NS & 0.043 & \\
\hline \multicolumn{5}{|l|}{ ALT (U/L) } \\
\hline Baseline, mean (SD) & $20(15.8)$ & $19.8(16.6)$ & $20.1(17)$ & NS \\
\hline End of treatment, mean (SD) & $22.8(15.5)$ & $19.3(15.4)$ & $26.2(16.7)$ & $<0.001$ \\
\hline Patients with any increase, $\mathrm{n}$ (\%) & $277(55.4)$ & $64(25.9)$ & $213(84.2)$ & $<0.001$ \\
\hline Absolute difference, mean (SD) & $2.8(10.4)$ & $-0.5(8.2)$ & $6.1(12.1)$ & $<0.001$ \\
\hline Relative difference (percentage), mean (SD) & $14(28.4)$ & $-2.5(34.6)$ & $30.3(32.3)$ & $<0.001$ \\
\hline Significance & - & NS & 0.002 & \\
\hline \multicolumn{5}{|l|}{ GGT (U/L) } \\
\hline Baseline, mean (SD) & $20.9(20)$ & $21(20.4)$ & $20.7(18.6)$ & NS \\
\hline End of treatment, mean (SD) & $22.7(20.6)$ & $20.1(20.7)$ & $25.2(20.6)$ & $<0.001$ \\
\hline Patients with any increase, $\mathrm{n}(\%)$ & $238(47.6)$ & $74(30)$ & $164(64.8)$ & $<0.001$ \\
\hline Absolute difference, mean (SD) & I.8 (II.5) & $-0.9(10.4)$ & $4.5(12.4)$ & $<0.001$ \\
\hline Relative difference (percentage), mean (SD) & $8.6(31.1)$ & $-4.3(36.6)$ & $21.7(39.3)$ & $<0.001$ \\
\hline Significance & - & NS & 0.046 & \\
\hline
\end{tabular}

Notes: Data show absolute scores for hemoglobin, hematocrit, erythrocyte count, AST, ALT, and GGT at baseline vs. end-of-treatment, absolute and relative (percent) changes vs. baseline, and the proportion of patients with any deterioration at study end vs. baseline. Data given for the whole laboratory population (All) and both treatment groups (OEC vs DIC).

Abbreviations: LOCF, last observation carried forward; OEC, oral enzyme combination; DIC, diclofenac; SD, standard deviation; NS, not significant.

$0.3125 / 0.2662$ points), and demonstrated noninferiority of both treatments up to a very narrow margin not only for the ITT population ( 0.7253 points) but also for the more conservative PP population ( 0.7422 points). Both treatment groups showed an improvement in more than $75 \%$ of patients, reaching $\geq 30 \% / 50 \%$ decrease in complaints at study end vs baseline in $39.7 \% / 23.6 \%$ of OEC patients and in $41 \% / 24.1 \%$ of DIC patients. In parallel, PIR and PIM improved significantly during the course of both study treatments, and two-thirds of patients in both groups reported a relief PIM greater than the MCID for the $\mathrm{NRS}_{11}$ pain-intensity scale used, indicating not only biometrically significant but also clinically relevant treatment effects, even more important for individual patients.

Both OEC and DIC have been reported to exhibit antiphlogistic effects, essential not only for the acute treatment of OA flares but also important to reduce disease progression over time ${ }^{58-60}$ While DIC induces its anti-inflammatory activity primarily via systemic inhibition of $\mathrm{COX} 2,{ }^{61-63}$ the 


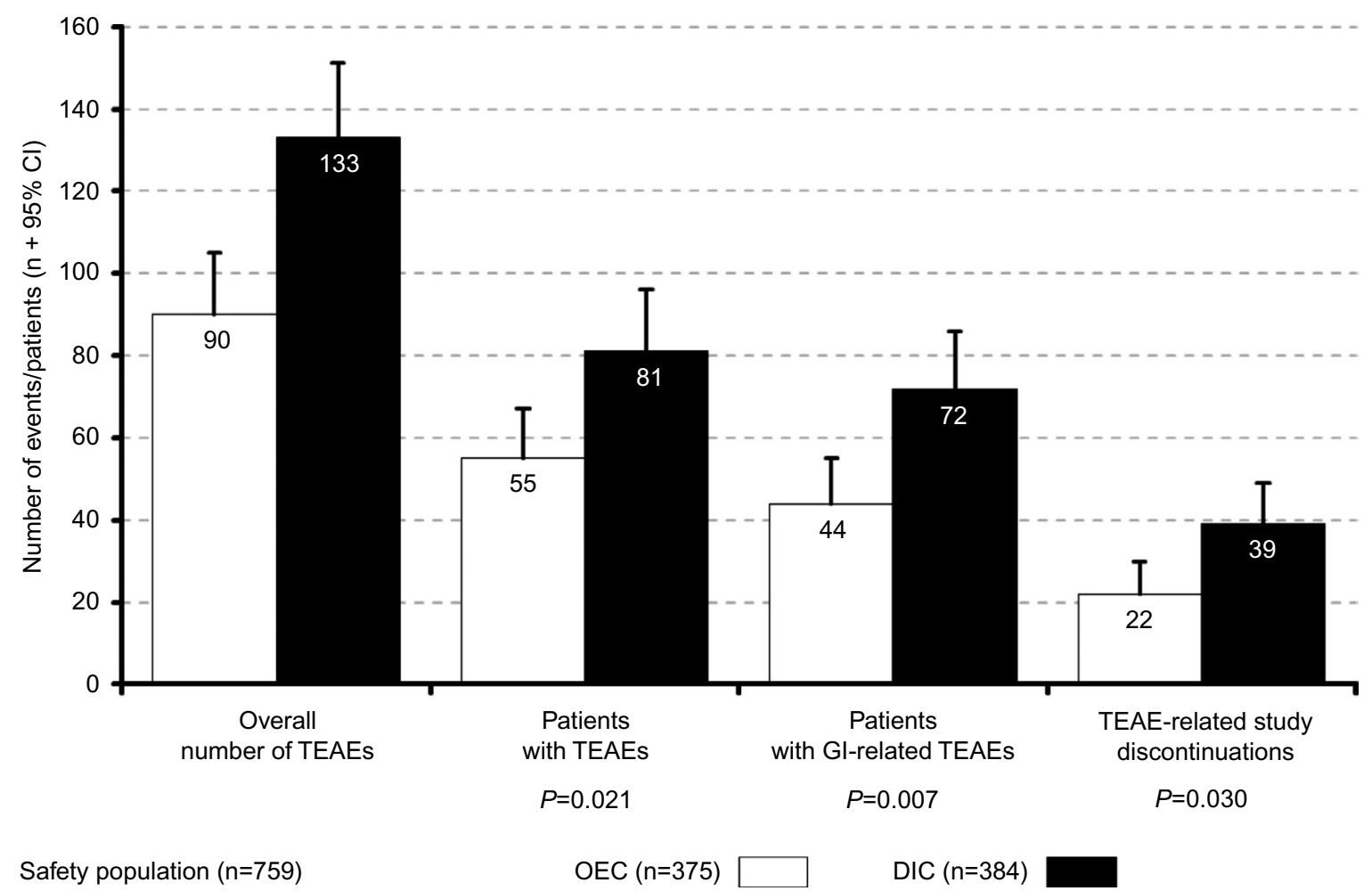

Figure 6 Treatment-emergent adverse event (TEAE) box plots.

Notes: Data given for the laboratory population and patients treated with either the oral enzyme combination (OEC; white columns) or with diclofenac (DIC; black columns). Abbreviations: $\mathrm{Cl}$, confidence interval; GI, gastrointestinal; OEC, oral enzyme combination; DIC, diclofenac.

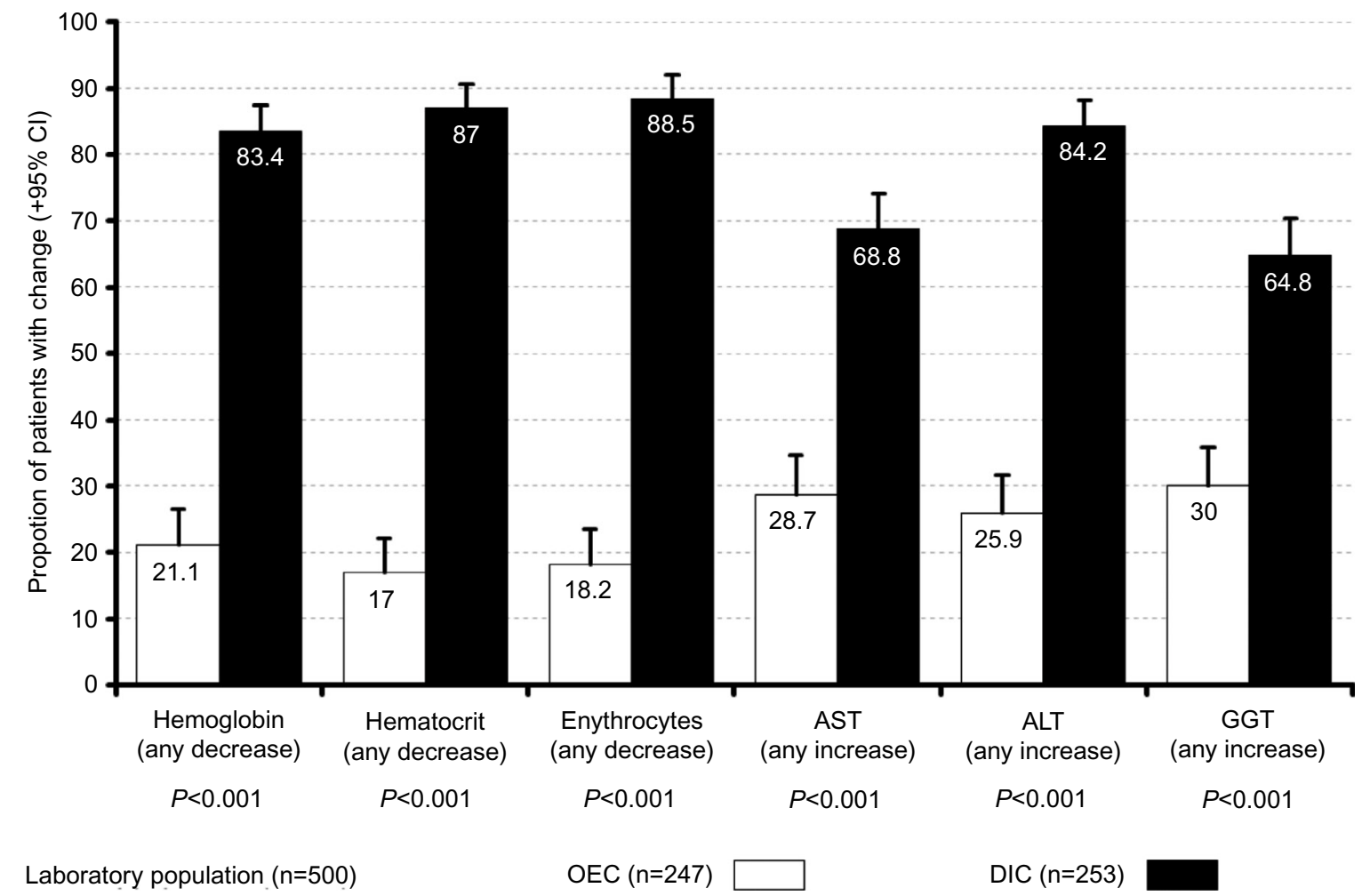

Figure 7 Parameter-change box plots.

Notes: Proportion (+95\% confidence intervals [Cls]) of patients who presented with a decrease in hemoglobin, hematocrit, or erythrocytes, or an increase in AST, ALT, or GGT at study end vs baseline. Data given for the laboratory population and patients treated either with the oral enzyme combination (OEC; white columns) or with diclofenac (DIC; black columns).

Abbreviations: $\mathrm{Cl}$, confidence interval; $\mathrm{GI}$, gastrointestinal; OEC, oral enzyme combination; DIC, diclofenac. 


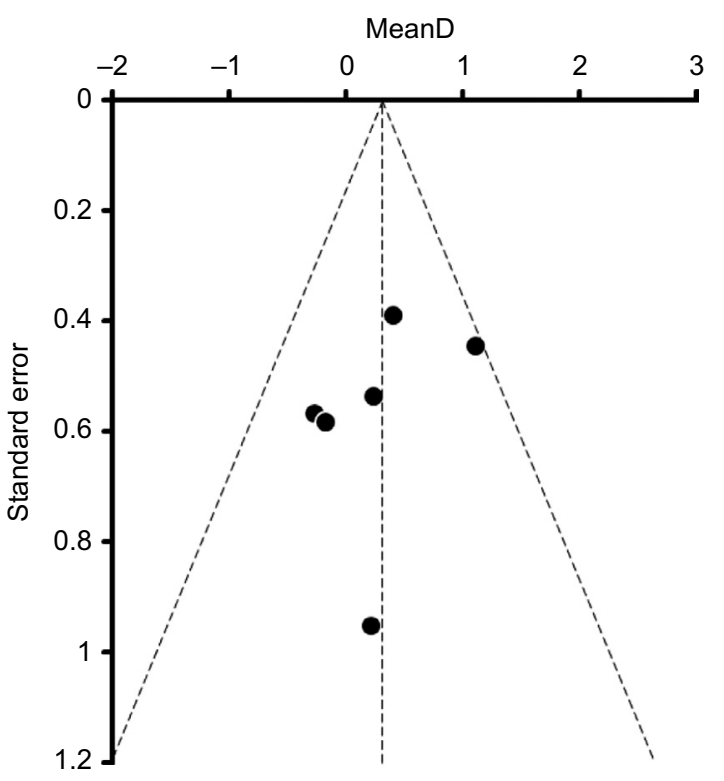

Fixed effects (Hedges-Olkin $\left.{ }^{38}\right)=0.3125(-0.1003$ to 0.7253$)$

Figure 8 Funnel plot with $95 \%$ confidence intervals

Notes: Data from six randomized controlled trials ${ }^{19-24}$ comparing oral enzyme combination vs diclofenac with respect to Lequesne algofunctional index: changes from baseline (analysis of covariance); effect size (mean difference); and lastobservation-carried-forward data set (intent-to-treat population).

mechanisms of OEC action are yet not fully understood, and its clinical (analgesic, antiedematous, anti-inflammatory, antioxidant, and fibrinolytic) influences probably depend on the combination of different effects, propagated by its polyphenolic (rutoside) and hydrolytic enzyme constituents (bromelain and trypsin): while bromelain decreases neutrophil migration, secretion of proinflammatory cytokines, reduces platelet aggregation, and exhibits fibrinolytic activities in dissolving fibrin clots, ${ }^{64-69}$ trypsin demonstrates antioxidant effects, influences the activation of PAR2, and decreases the inflammatory response in animal models and in studies with allergic respiratory disease, ${ }^{70-72}$ and the flavonoid rutoside shows antioxidative, anti-inflammatory, and antimicrobial effects. ${ }^{73-76}$ Based on the results of this IPD meta-analysis, the beneficial anti-inflammatory and analgesic effects of OEC were comparable to those of DIC, one of the most prevalently prescribed NSAIDs for OA worldwide, in 2013 responsible for 356 million defined daily doses in Germany alone, corresponding to $\sim 35 \%$ of the overall national German NSAID prescriptions in that year. ${ }^{77}$

In contrast to their comparable functional and analgesic efficacy, treatment groups differed significantly with respect to the primary safety and laboratory end points in this analysis. The number of TEAEs and percentages of patients with TEAEs were significantly greater with DIC vs OEC and nearly twice as many DIC patients affected by
TEAEs discontinued prematurely in comparison to those reported for OEC. Not surprisingly, DIC-related TEAEs most prevalently affected the GI system, and for that distinct organ class both the overall number of TEAEs ( $n=101$ vs $61, P<0.001)$ and the number of patients affected $(\mathrm{n}=72 \mathrm{vs}$ $44,18.8 \%$ vs $11.7 \% ; P=0.007$ ) were significantly higher for DIC vs OEC. However, significant between-group DIC vs OEC differences were also found for patients affected by TEAEs categorized toward the organ classes "investigations" ( $\mathrm{n}=12$ vs $3,3.1 \%$ vs $0.8 \% ; \mathrm{p}=0.021)$ and "cardiac system" ( $\mathrm{n}=6$ vs $0,1.6 \%$ vs $0 ; P=0.015$ ), underlining the complex interactions of COX inhibition with physiological body function.

Abnormalities in hepatic function are another concern with longer-term DIC therapy, especially in elderly patients using multiple pharmacological treatments to address the increasing occurrence of different comorbidities. DIC but not OEC treatment was associated in the majority of patients with noticeable and statistically highly significant increases of the key liver enzymes AST, ALT, and GGT at study end vs baseline. From a clinical point of view, these laboratory changes were for individual patients mostly irrelevant. Except for those 12 patients (3.1\%) with laboratory abnormalities classified as TEAEs, DIC-related laboratory changes were usually below the upper reference ranges reported for these parameters evaluated, and none of the patients reported any related clinical complaints suggestive for hepatic failure. From that point of view, these between-sample differences seen for patients without further pathological findings would not usually raise any concerns in daily life. However, within the patient population evaluated during this IPD meta-analysis, DIC-related laboratory effects were highly prevalent, consistent between parameters evaluated, and significantly different from those effects seen with OEC, generating critical questions about its safety profile, especially if the relatively short treatment duration (3-12 weeks) is taken into account. Comparable, if at all less extensive observations on DIC-related changes in hepatic enzymes were reported by Klein et al, who found at the end of their 6-week treatment with DIC an average \pm SD ALT increase of $2.2 \pm 8.5 \mathrm{U} / \mathrm{L},{ }^{77}$ and a pooled safety analysis reported average \pm SD changes of $1.87 \pm 13.7 \mathrm{U} / \mathrm{L}$ for ALT and 2.94 $\pm 14.3 \mathrm{U} / 1$ for AST in elderly OA patients treated with oral DIC for 4-12 weeks. ${ }^{79}$

The prevalence of elevated liver enzymes in our study was significantly higher than those reported by others, who published DIC-related increases of hepatic enzymes in up to $15 \%$ of patients treated chronically, ${ }^{80-82}$ an increase beyond 
three times the upper reference range in $2 \%-4 \%$ of patients, ${ }^{83}$ and a clinically relevant DIC-related hepatotoxicity in about six per 100,000 DIC users. ${ }^{84}$ This can be explained by differences in sample size, study design, and especially event definition. In our analysis, we counted every change vs baseline as a "signal" (irrespective of its magnitude), while others preferred to count only increases beyond the upper reference range. The pathogenesis of DIC-induced hepatotoxicity is still not fully understood; however, a combination of direct toxic effects (caused by DIC metabolites) and indirect toxicity (caused by inflammatory processes) have been suggested to be responsible for the hepatocellular pattern of liver injury seen with DIC.$^{85}$ Despite their subclinical relevance, the highly prevalent and consistent changes in liver enzymes detected in this IPD meta-analysis following short- to intermediate-term treatment with DIC have to be taken as a warning signal for the critical constellation that NSAID-induced hepatotoxicity increases with age and the circumstance that NSAIDs are increasingly prescribed, particular among elderly patients. ${ }^{86,87}$

The DIC-associated observation of a decrease in hemoglobin, hematocrit, and erythrocyte count may be explained as laboratory correlates of treatment-related mucosal lesions of the intestine and subsequent blood loss via the GI system. Prevalence and excess of changes were comparable to those reported by Roth and Fuller in their studies on DIC safety in OA. ${ }^{79,88}$ Subclinical GI blood loss is a common consequence of NSAID treatment, and predominantly is not caused by NSAID effects on the upper GI tract, but rather by topical side effects in the small intestine, where the enterohepatic circulation of NSAIDs increases their exposure toward the mucosal epithelium. ${ }^{89-91}$ Proven consequences are silent mucosal inflammation, reduced blood flow, epithelial damage, mucosal injury, increased mucosal permeability, malabsorption, protein loss, and occult blood loss (with an associated decrease in hemoglobin), reported for more than $50 \%$ of patients on NSAIDs or low-dose aspirin. ${ }^{92-94}$ The clinical significance of these NSAID-related TEAEs on the lower GI tract are poorly characterized compared to those of the upper tract; however, they must not be underestimated, as studies have reported a similar or even higher mortality for complications arising from the lower when compared with those of the upper GI tract. ${ }^{95,96}$ At present, effective means to prevent NSAID-related intestinal lesions are not available. Therefore, based on the currently available data, treatment with an equally effective but significantly better-tolerated agent, such as OEC, seems to be a reasonable alternative for OA patients who need anti-inflammatory therapy.

\section{Limitations}

One of the major limitations of this IPD meta-analysis was the lack of an adequate placebo group. As only one of those six studies included in this report contained placebo data, ${ }^{24}$ the aggregation of a representative placebo patient group for treatment-effect comparisons was impossible. Currently, a matched triple analysis (OEC vs DIC vs placebo) is scheduled to gain further insight into the efficacy and tolerability of OEC and DIC compared with placebo, but analyses are not yet finished and results will be published later. However, efficacy results reported for DIC - a well-established and prevalently prescribed NSAID for OA treatment - were in line with those data published for its activity in placebo-controlled trials and gave no cause for serious concerns about a relevant or inadequate overestimation of treatment effects.

Another critical issue is the apparent lack of long-term data. The data presented indicate an equivalent efficacy and superior safety/tolerability profile of OEC vs DIC for a treatment period of up to 12 weeks, and suggest comparable effects with repeated and ongoing effects with prolonged use.

However, the moderate lengths of the OEC studies included give neither formal evidence for a sustained efficacy comparable to DIC beyond a treatment duration of 12 weeks nor for the maintenance of a safety and tolerability profile superior to that of DIC. While some data support safe and efficacious longterm use of OEC for durations up to 1-5 years, the number of studies is limited and patients enrolled suffered from different disease conditions (eg, rheumatoid arthritis, multiple sclerosis) not really comparable to OA. ${ }^{97-99}$ Due to that, adequate studies evaluating repeated and long-term use are necessary to confirm whether OEC is also over an extended period of time an adequate alternative to DIC in adults suffering from OA.

\section{Conclusion}

This is the first IPD meta-analysis aggregating patient-level data on the efficacy, tolerability, and safety of OEC vs DIC in adult populations suffering from $\mathrm{OA}$. The results obtained from six randomized controlled trials lasting 3-12 weeks demonstrated for both treatment groups comparable efficacy and clinically relevant improvement with respect to knee-joint pain and pain-related restrictions in daily life functioning. OEC presented with a significantly superior safety profile vs DIC, characterized by a lower prevalence of TEAEs, fewer patients affected by TEAEs, and fewer TEAE-related treatment discontinuations. In addition, laboratory evaluation of data from blood samples taken at baseline and study end showed virtually no OEC-related changes, while treatment with DIC was followed by changes in key hepatic enzymes 
in $\sim 72.6 \%$ and red blood parameters in $\sim 86.3 \%$ of patients. This overall superior risk-benefit profile qualifies OEC not only as an alternative OA treatment to DIC and other NSAIDs in high-risk patients but also as a safe and efficacious option for the daily management of OA-related joint pain.

\section{Acknowledgement}

The concept for this meta-analysis was developed by the Institute of Neurological Sciences, Algesiology, and Pediatrics on behalf of the German Pain Association (Deutsche Gesellschaft für Schmerzmedizin [DGS]) and the German Pain League (Deutsche Schmerzliga [DSL]). The original studies were realized by independent contract-research organizations and sponsored by Mucos Pharma, Germany. Neither the sponsor of the original studies nor any of its employees exerted any influence on the conduct of the study, nor on analyses, interpretation, and publication of the results.

\section{Disclosure}

MAU, GHHMS, and RW are physicians and independent of any significant/relevant financial or other relationship to the sponsor, except for minor reimbursements for occasional lecture or consulting fees. UE is CEO of an independent consultancy agency. The authors report no other conflicts of interest.

\section{References}

1. Bijlsma JW, Berenbaum F, Lafeber FP. Osteoarthritis: an update with relevance for clinical practice. Lancet. 2011;377:2115-2126.

2. Pereira D, Peleteiro B, Araújo J, Branco J, Santos RA, Ramos E. The effect of osteoarthritis definition on prevalence and incidence estimates: a systematic review. Osteoarthritis Cartilage. 2011;19:1270-1285.

3. Centers for Disease Control and Prevention. Osteoarthritis (OA). 2015. Available from: http://www.cdc.gov/arthritis/basics/osteoarthritis.htm. Accessed January 30, 2016.

4. Jordan KM, Arden NK, Doherty M, et al. EULAR recommendations 2003:an evidence based approach to the management of knee osteoarthritis: report of a task force of the Standing Committee for International Clinical Studies Including Therapeutic Trials (ESCISIT). Ann Rheum Dis. 2003;62:1145-1155.

5. Hochberg MC, Altman RD, April KT, et al. American College of Rheumatology 2012 recommendations for the use of nonpharmacologic and pharmacologic therapies in osteoarthritis of the hand, hip, and knee. Arthritis Care Res. 2012;64:465-474.

6. Zhang W, Moskowitz RW, Nuki G, et al. OARSI recommendations for the management of hip and knee osteoarthritis, part I: critical appraisal of existing treatment guidelines and systematic review of current research evidence. Osteoarthritis Cartilage. 2007;15:981-1000.

7. Zhang W, Moskowitz RW, Nuki G, et al. OARSI recommendations for the management of hip and knee osteoarthritis, part II: OARSI evidence-based, expert consensus guidelines. Osteoarthritis Cartilage. 2008;16:137-162.

8. Zhang W, Nuki G, Moskowitz RW, et al. OARSI recommendations for the management of hip and knee osteoarthritis, part III: changes in evidence following systematic cumulative update of research published through January 2009. Osteoarthritis Cartilage. 2010;18: 476-499.
9. McAlindon TE, Bannuru RR, Sullivan MC, et al. OARSI guidelines for the non-surgical management of knee osteoarthritis. Osteoarthritis Cartilage. 2014;22:363-388.

10. National Collaborating Centre for Chronic Conditions. Osteoarthritis: National Clinical Guidelines for Care and Management in Adults. London: Royal College of Physicians; 2008.

11. National Institute for Health and Care Excellence. Osteoarthritis: Care and Management. London: NICE; 2014.

12. Moore N. Diclofenac potassium $12.5 \mathrm{mg}$ tablets for mild to moderate pain and fever: a review of its pharmacology, clinical efficacy and safety. Clin Drug Investig. 2007;27:163-195.

13. Moore N, Charlesworth A, Van Ganse E, et al. Risk factors for adverse events in analgesic drug users: results from the PAIN study. Pharmacoepidemiol Drug Saf. 2003;12:601-610.

14. Moore N, Van Ganse E, Le Parc J, et al. Paracetamol, Aspirin and Ibuprofen New tolerability study. A large scale, randomized clinical trial comparing the tolerability of aspirin, ibuprofen and paracetamol for short-term analgesia. Clin Drug Investig. 1999;18:89-98.

15. Schaffer D, Florin T, Eagle C, et al. Risk of serious NSAID-related gastrointestinal events during long-term exposure: a systematic review. Med J Aust. 2006;185:501-506.

16. Singh G, Wu O, Langhorne P, Madhok R. Risk of acute myocardial infarction with nonselective non-steroidal anti-inflammatory drugs: a meta-analysis. Arthritis Res Ther. 2006;8:R153.

17. Wolfe MM, Lichtenstein DR, Singh G. Gastrointestinal toxicity of nonsteroidal antiinflammatory drugs. N Engl J Med. 1999;340:1888-1899.

18. Singer F, Oberleitner H. Ein Beitrag zur medikamentösen Therapie der aktivierten Arthrose. Zur Effektivität eines Enzymgemisches vs. Diclofenac [Drug therapy of activated arthrosis: on the effectiveness of an enzyme mixture versus diclofenac]. Wien Med Wochenschr. 1996;146: 55-58. German.

19. Singer F, Singer C, Oberleitner H. Phlogenzym versus diclofenac in the treatment of activated osteoarthritis of the knee: a double-blind prospective randomized study. Int J Immunother. 2001;17:135-141.

20. Akhtar NM, Naseer R, Farooqi AZ, Aziz W, Nazir M. Oral enzyme combination versus diclofenac in the treatment of osteoarthritis of the knee: a double-blind prospective randomized study. Clin Rheumatol. 2004:23:410-415.

21. Klein G, Kullich W. Short-term treatment of painful osteoarthritis of the knee with oral enzymes: a randomized, double-blind study versus diclofenac. Clin Drug Investig. 2000;19:15-23.

22. Herrera EG. Phlogenzym in the treatment of a monoarticular painful gonarthritis: efficacy and tolerance. 1998. Available from: http://www. wobenzym.cz/cdweb/mucos/pittompg.htm. Accessed June 12, 2016.

23. Roth SH, Stauder GM. Oral enzyme therapy (Phlogenzym) in osteoarthritis: long-term comparative study against diclofenac. Poster presented at: 65th Annual Scientific Meeting of the American College of Rheumatology; November 11-15, 2001; San Francisco, CA.

24. Bolten WW, Glade MJ, Raum S, Ritz BW. The safety and efficacy of an enzyme combination in managing knee osteoarthritis pain in adults: a randomized, double-blind, placebo-controlled trial. Arthritis 2015;2015:251521.

25. International Union of Biochemistry. Nomenclature Committee: Enzyme Nomenclature. London: Academic Press; 1984.

26. OCR Systeme GmbH. FormPro 3.0: Data capture from forms and questionnaires. Available from: http://www.ocr-systeme.de/english/ formpro. Accessed June 12, 2016.

27. US Food and Drug Administration. Guidance for industry: clinical development programs for drugs, devices, and biological products intended for the treatment of osteoarthritis (OA). 1999. Available from: http://www.fda.gov/downloads/Drugs/GuidanceComplianceRegulatoryInformation/Guidances/UCM071577.pdf. Accessed June 12, 2016.

28. European Medicines Agency. Guideline on clinical investigation of medicinal products used in the treatment of osteoarthritis. 2010. Available from: http://www.ema.europa.eu/docs/en_GB/document_library/ Scientific_guideline/2009/09/WC500003440.pdf. Accessed June 12, 2016.

29. Lequesne MG. The algofunctional indices for hip and knee osteoarthritis. J Rheumatol. 1997;24:779-781. 
30. MedDRA [website on the Internet]. Available from: http://www.meddra. org. Accessed January 16, 2016.

31. Bellamy N, Carr A, Dougados M, Shea B, Wells G. Towards a definition of "difference" in osteoarthritis. J Rheumatol. 2001;28:427-430.

32. Tubach F, Ravaud P, Baron G, et al. Evaluation of clinically relevant changes in patient reported outcomes in knee and hip osteoarthritis: the minimal clinically important improvement. Ann Rheum Dis. 2005; 64:29-33.

33. Engels JM, Diehr P. Imputation of missing longitudinal data: a comparison of methods. J Clin Epidemiol. 2003;56:968-976.

34. McKnight PE, McKnight KM, Sidani S, Figueredo AJ. Missing Data: A Gentle Introduction. New York: Guilford Press; 2007.

35. Demirtas H, Hedeker D. An imputation strategy for incomplete longitudinal ordinal data. Stat Med. 2008;27:4086-4093.

36. Holm S. A simple sequentially rejective multiple test procedure. Scand Stat Theory Appl. 1979;6:65-70.

37. Gail M, Simon R. Testing for qualitative interactions between treatment effects and patient subsets. Biometrics. 1985;41:361-372.

38. Hedges LV, Olkin I. Statistical Methods for Meta-analysis. Orlando: Academic Press; 1985.

39. DerSimonian R, Laird N. Meta-analysis in clinical trials. Control Clin Trials. 1986;7:177-188.

40. DerSimonian R, Laird N. Meta-analysis in clinical trials revisited. Contemp Clin Trials. 2015;45:139-145.

41. Light RJ, Pillemer DB. Summing Up: The Science of Reviewing Research. Cambridge (MA): Harvard University Press; 1984.

42. Egger M, Smith GD, Schneider M, Minder C. Bias in meta-analysis detected by a simple, graphical test. BMJ. 1997;315:629-624.

43. Sterne JA, Egger M. Funnel plots for detecting bias in meta-analysis: guidelines on choice of axis. J Clin Epidemiol. 2001;54:1046-1045.

44. Moskowitz RW. The burden of osteoarthritis: clinical and quality-of-life issues. Am J Manag Care. 2009;15:S223-S229.

45. Guccione AA, Felson DT, Anderson JJ, et al. The effects of specific medical conditions on the functional limitations of elders in the Framingham study. Am J Public Health. 1994;84:351-358.

46. Jordan J, Luta G, Renner J, Dragomir A, Hochberg M, Fryer J. Knee pain and knee osteoarthritis severity in self-reported task specific disability: the Johnston County Osteoarthritis Project. J Rheumatol. 1997;24:1344-1349.

47. van Dijk GM, Veenhof C, Schellevis F, et al. Comorbidity, limitations in activities and pain in patients with osteoarthritis of the hip or knee. BMC Musculoskelet Disord. 2008;9:95.

48. Spector TD, Hart DJ, Nandra D, et al. Low-level increases in serum C-reactive protein are present in early osteoarthritis of the knee and predict progressive disease. Arthritis Rheum. 1997;40:723-727.

49. Pelletier JP, Martel-Pelletier J, Abramson SB. Osteoarthritis, an inflammatory disease: potential implication for the selection of new therapeutic targets. Arthritis Rheum. 2001;44:1237-1247.

50. Warner TD, Giuliano F, Vojnovic I, Bukasa A, Mitchell JA, Vane JR. Nonsteroid drug selectivities for cyclooxygenase-1 rather than cyclooxygenase- 2 are associated with human gastrointestinal toxicity: a full in vitro analysis. Proc Natl Acad Sci U S A. 1999;96:7563-7568.

51. Sycha T, Gustorff B, Lehr S, Tanew A, Eichler HG, Schmetterer L. A simple pain model for the evaluation of analgesic effects of NSAIDs in healthy subjects. Br J Clin Pharmacol. 2003;56:165-172.

52. Chen YF, Jobanputra P, Barton P, et al. Cyclooxygenase-2 selective non-steroidal anti-inflammatory drugs (etodolac, meloxicam, celecoxib, rofecoxib, etoricoxib, valdecoxib and lumiracoxib) for osteoarthritis and rheumatoid arthritis: a systematic review and economic evaluation. Health Technol Assess. 2008;12:1-278, iii.

53. Niculescu L, Li C, Huang J, Mallen S. Pooled analysis of GI tolerability of 21 randomized controlled trials of celecoxib and nonselective NSAIDs. Curr Med Res Opin. 2009;25:729-740.

54. Mukherjee D, Nissen SE, Topol EJ. Risk of cardiovascular events associated with selective COX-2 inhibitors. JAMA. 2001;286: 954-959.
55. Nüesch E, Dieppe P, Reichenbach S, Williams S, Iff S, Jüni P. All cause and disease specific mortality in patients with knee or hip osteoarthritis: population based cohort study. BMJ. 2011;342:d1165.

56. Antman EM, Bennett JS, Daugherty A, Furberg C, Roberts H, Taubert KA. Use of nonsteroidal antiinflammatory drugs: an update for clinicians: a scientific statement from the American Heart Association. Circulation. 2007;115:1634-1642.

57. Altman RD. Practical considerations for the pharmacologic management of osteoarthritis. Am J Manag Care. 2009;15:S236-S243.

58. Mazourov VI, Lila AM, Klimko NN, Raimuev KV, Makulova TG. The efficacy of systemic enzyme therapy in the treatment of rheumatoid arthritis. Int J Immunother. 1997;13:85-91.

59. Friedrich F. "Therapie der chronischen Adnexitis: Diclofenac oder Enzyme? Randomisierte doppelblinde Parallelgruppenstudie gegen Diclofenac. Allgemeinarzt. 1993;17:1061-1064.

60. Lackovic V, Rovensky J, Horvathová M, Malis F. Interferon production in whole blood cultures from volunteers and rheumatoid arthritis patients after medication with oral enzymes. Int J Immunother. 1997;13:159-165.

61. Vane JR. Inhibition of prostaglandin synthesis as mechanism of action for aspirin-like drugs. Nat New Biol. 1971;231:232-235.

62. Vane JR, Botting RM. New insights into mode of action of antiinflammatory drugs. Inflamm Res. 1995;44:1-10.

63. Vane JR, Botting RM. Mechanism of action of nonsteroidal antiinflammatory drugs. Am J Med. 1998;104:S2-S8.

64. Livio M, Bertoni MP, DeGaetano G. Effect of bromelain on fibrinogen level, prothrombin complex factors and platelet aggregation in the rat: a preliminary report. Drugs Exp Clin Res. 1978;4:49-53.

65. Metzig C, Grabowska E, Eckert K, Rehse K, Maurer HR. Bromelain proteases reduce human platelet aggregation in vitro, adhesion to bovine endothelial cells and thrombus formation in rat vessels in vivo. In Vivo. 1999;13:7-12.

66. Maurer HR. Bromelain: biochemistry, pharmacology and medical use. Cell Mol Life Sci. 2001;58:1234-1245.

67. Braun JM, Schneider B, Beuth HJ. Therapeutic use, efficiency and safety of the proteolytic pineapple enzyme Bromelain-POS $₫$ in children with acute sinusitis in Germany. In Vivo. 2005;19:417-421.

68. Fitzhugh DJ, Shan S, Dewhirst MW, Hale LP. Bromelain treatment decreases neutrophil migration to sites of inflammation. Clin Immunol. 2008;128:66-74.

69. Onken JE, Greer PK, Calingaert B, Hale LP. Bromelain treatment decreases secretion of pro-inflammatory cytokines and chemokines by colon biopsies. In Vitro Clin Immunol. 2008;126:345-352.

70. McLean PG, Aston D, Sarkar D, Ahluwalia A. Protease-activated receptor-2 activation causes EDHF-like coronary vasodilation: selective preservation in ischemia/reperfusion injury - involvement of lipoxygenase products, VR1 receptors, and C-fibers. Circ Res. 2002;90: 465-472.

71. Reed CE, Kita H. The role of protease activation of inflammation in allergic respiratory diseases. J Allergy Clin Immunol. 2004;114:997-1008.

72. Neumayer C, Fügl A, Nanobashvili J, et al. Combined enzymatic and antioxidative treatment reduces ischemia-reperfusion injury in rabbit skeletal muscle. J Surg Res. 2006;133:150-158.

73. Pagonis C, Tauber AI, Pavlotsky N, Simons ER. Flavonoid impairment of neutrophil response. Biochem Pharmacol. 1986;35:237-245.

74. Kuo SM. Dietary flavonoid and cancer prevention: evidence and potential mechanism. Crit Rev Oncog. 1997;8:47-69.

75. Bazzano LA, He J, Ogden LG, et al. Fruit and vegetable intake and risk of cardiovascular disease in US adults: the first National Health and Nutrition Examination Survey epidemiologic follow-up study. $\mathrm{Am}$ J Clin Nutr. 2002;76:93-99.

76. Lotito SB, Frei B. Consumption of flavonoid-rich foods and increased plasma antioxidant capacity in humans: cause, consequence, or epiphenomenon? Free Radic Biol Med. 2006;41:1727-1746.

77. Böger RH, Schmidt G. Antirheumatika undAntiphlogistika. In: SchwabeU, Paffrath D, editors. Arzneiverordnungs - Report 2014. Heidelberg: Springer; 2014. 
78. Klein G, Kullich W, Schnitker J, Schwann H. Efficacy and tolerance of an oral enzyme combination in painful osteoarthritis of the hip: a double-blind, randomized study comparing oral enzymes with nonsteroidal anti-inflammatory drugs. Clin Exp Rheumatol. 2006;24: 25-30.

79. Roth SH, Fuller P. Pooled safety analysis of diclofenac sodium topical solution $1.5 \%(\mathrm{w} / \mathrm{w})$ in the treatment of osteoarthritis in patients aged 75 years or older. Clin Interv Aging. 2012;7:127-137.

80. Ciccolunghi SN, Chaudri HA, Schubiger BI, Reddrop R. Report on a long-term tolerability study of up to two years with diclofenac sodium (Voltaren). Scand J Rheumatol Suppl. 1978;22:86-96.

81. Grossner T, Smyth EM, Fitzgerald GA. Anti-inflammatory, antipyretic, and analgesic agents: pharmacotherapy of gout. In: Brunton LL, Chabner BA, Knollman BC, editors. Goodman and Gilman's: The Pharmacological Basis of Therapeutics. 12th ed. New York: McGraw-Hill; 2011:959-1004.

82. Lewis JH, Stine JG. Nonsteroidal anti-inflammatory drugs and leukotriene receptor antagonists: pathology and clinical presentation of hepatotoxicity. In: Kaplowitz N, DeLeve LD, editors. Drug-Induced Liver Disease. 3rd ed. Amsterdam: Elsevier; 201:370-402.

83. Laine L, Goldkind L, Curtis SP, Connors LG, Yanqiong Z, Cannon CP. How common is diclofenac-associated liver injury? Analysis of 17,289 arthritis patients in a long-term prospective clinical trial. Am J Gastroenterol. 2009;104:356-362.

84. de Abajo FJ, Montero D, Madurga M, García Rodríguez LA. Acute and clinically relevant drug-induced liver injury: a population based case-control study. Br J Clin Pharmacol. 2004;58:71-80.

85. Aithal GP, Day CP. Nonsteroidal anti-inflammatory drug-induced hepatotoxicity. Clin Liver Dis. 2007;11:563-575.

86. American Geriatrics Society Panel on the Pharmacological Management of Persistent Pain in Older Persons. Pharmacological management of persistent pain in older persons. JAm Geriatr Soc. 2009;57:1331-1346.

87. Jones R. Nonsteroidal anti-inflammatory drug prescribing: past, present, and future. Am J Med. 2001;110(1A):4S-7S.

88. Roth SH, Fuller P. Diclofenac topical solution compared with oral diclofenac: a pooled safety analysis. J Pain Res. 2011;4:159-167.
89. Lichtenberger LM. The hydrophobic barrier properties of gastrointestinal mucus. Annu Rev Physiol. 1995;57:565-583.

90. Lichtenberger LM. Where is the evidence that cyclooxygenase inhibition is the primary cause of nonsteroidal anti-inflammatory drug (NSAID)induced gastrointestinal injury? Topical injury revisited. Biochem Pharmacol. 2001;61:631-637.

91. Smecuol E, Bai JC, Sugai E, et al. Acute gastrointestinal permeability responses to different non-steroidal anti-inflammatory drugs. Gut 2001;49:650-655.

92. Laine L, Connors LG, Reicin A, et al. Serious lower gastrointestinal clinical events with nonselective NSAID or coxib use. Gastroenterology. 2003;124:288-292.

93. Goldstein JL, Eisen GM, Lewis B, Gralnek IM, Zlotnick S, Fort JG. Video capsule endoscopy to prospectively assess small bowel injury with celecoxib, naproxen plus omeprazole, and placebo. Clin Gastroenterol Hepatol. 2005;3:133-141.

94. Smecuol E, Sanchez MI, Suarez A, et al. Low-dose aspirin affects the small bowel mucosa: results of a pilot study with a multidimensional assessment. Clin Gastroenterol Hepatol. 2009;7:524-529.

95. Laine L, Smith R, Min K, Chen C, Dubois RW. Systematic review: the lower gastrointestinal adverse effects of non-steroidal anti-inflammatory drugs. Aliment Pharmacol Ther. 2006;24:751-767.

96. Lanas A, García-Rodríguez LA, Polo-Tomás M, et al. Time trends and impact of upper and lower gastrointestinal bleeding and perforation in clinical practice. Am J Gastroenterol. 2009;104:1633-1641.

97. Klein G, Kullich W, Schwann H. Double-blind trial of an enzyme therapy versus oral gold in rheumatoid arthritis. Clinicum. 1995:2-8.

98. Kovalenko VB, Shuba NM, Golovatskiy IV, Bortkevich OP, Yasinskaya VA Estimation of efficacy of basic therapy of rheumatoid arthritis on the basis of systemic enzyme therapy: results of five-year monitoring. Int J Immunother. 2001;17:129-133.

99. Páz A, Zaborski J, Kruszewska-Ozimowska J, Członkowski A, Członkowska A. Analysis of peripheral blood leukocyte immunophenotype during oral hydrolytic enzyme treatment of multiple sclerosis patients. Int J Immunother. 2002;18:13-19.

\section{Journal of Pain Research}

\section{Publish your work in this journal}

The Journal of Pain Research is an international, peer reviewed, open access, online journal that welcomes laboratory and clinical findings in the fields of pain research and the prevention and management of pain. Original research, reviews, symposium reports, hypothesis formation and commentaries are all considered for publication

\section{Dovepress}

The manuscript management system is completely online and includes a very quick and fair peer-review system, which is all easy to use. Visit http://www.dovepress.com/testimonials.php to read real quotes from published authors. 